\title{
Targeting the osteoblast: approved and experimental anabolic agents for the treatment of osteoporosis
}

\author{
Konstantinos A. Toulis, ${ }^{1}$ Athanasios D. Anastasilakis, ${ }^{1}$ Stergios A. Polyzos, ${ }^{2}$ \\ Polyzois Makras ${ }^{3}$
}

${ }^{1}$ Department of Endocrinology \& Metabolism, 424 General Military Hospital, Thessaloniki, ${ }^{2}$ Second Medical Clinic, Medical School, Aristotle University of Thessaloniki, Ippokration Hospital, Thessaloniki, ${ }^{3}$ Department of Endocrinology \& Diabetes, 251 Hellenic Air Force \& VA General Hospital, Athens, Greece

\begin{abstract}
Targeting osteoblast may be the means of effectively improving both bone quality and mass, thus offering an intriguing alternative in the treatment of osteoporosis. Aside from injectable parathyroid hormone (PTH) and its novel preparations, PTH-related peptide (PTHrP), calcilytics, beta-adrenergic receptors, enhancement of Wnt signaling (mainly via sclerostin and Dickkopf-1 neutralization), regulation of low-density lipoprotein receptor-related protein (LPR) 5/osteoblast axis, activin, IGF-1, and bone morphogenic proteins (BMPs) are reviewed for their basic rationale and evidence of bone anabolic potential. Sclerostin neutralizing antibody, teriparatide transdermal patch, and PTHrP (1-36) are currently at an advanced stage of research. Safety and tissue specificity are the prerequisites in the development of a novel treatment, especially when addressing a chronic condition such as osteoporosis.
\end{abstract}

Key words: Anabolic treatment, Osteoblast, Osteoporosis, Parathyroid hormone, Sclerostin, Teriparatide

\section{INTRODUCTION}

In the normal skeleton, bone remodeling, the coordinated resorption and formation of skeletal tissue, is carried out by the osteoclasts and the osteoblasts, respectively, in the basic multicellular units. This

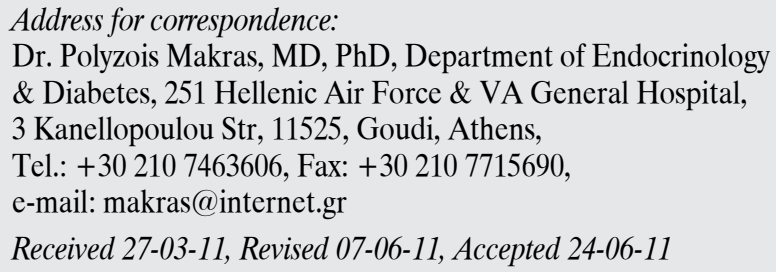

Received 27-03-11, Revised 07-06-11, Accepted 24-06-11

process is necessary for the maintenance of calcium homeostasis, microdamage repair, adaptation to mechanical loading, and removal of the aged tissue.

Age-related bone loss, independent of sex steroid status, which occurs as early as the third decade, ${ }^{1}$ is the net effect of an imbalance in bone remodeling such that bone resorption exceeds bone formation. This condition may eventually result in osteoporosis, which may be defined as the increased risk for fracture, resulting from decreased bone mass, along with deranged bone microarchitecture and compromised bone strength. ${ }^{2}$ In fact, osteoporosis 
is the leading cause of fractures, and interventions addressing this increased risk are found to be costeffective (http: //guidance.nice.org.uk/TA160). Since osteoporosis results from a bone remodeling state in which bone resorption exceeds bone formation, targeting osteoclasts (differentiation, proliferation, function, and life span) by antiresorptive agents, such as bisphosphonates, seems a reasonable choice. However, along with halting deterioration of bone microarchitecture, antiresorptive agents also inhibit formation, which is tightly coupled to resorption. ${ }^{3}$ Thus, important bone quality properties cannot be restored by targeting osteoclast. Hence the question arises as to whether or not targeting osteoblast would be a more appropriate intervention.

Intermittent parathyroid hormone (PTH) administration, the only currently available agent specifically targeting osteoblast, not only attains documented efficacy in increasing bone mass and preventing fractures ${ }^{4}$ but also improves bone quality. ${ }^{5}$ It is plausible to assume that such benefits might be expected from an agent that targets osteoblastic lineage (osteoblast commitment, differentiation, proliferation, function, and/or life span). This review aims at providing an overview of the currently available anabolic therapies and an insight into promising investigational anabolic therapies for the treatment of osteoporosis.

\section{PARATHYROID HORMONE}

\section{Background}

Human PTH is an 84-amino acid peptide playing a central role in the maintenance of calcium homeostasis. Parathyroid cells sense extracellular calcium concentration via the calcium-sensing receptors (CaSR) and secrete PTH in response to calcium levels decrease. Subsequently, PTH mobilizes calcium from skeletal stores, stimulates release of calcium (and phosphate) by activation of bone resorption, increases renal tubular calcium reabsorption, and indirectly enhances intestinal calcium absorption via its stimulatory action on renal $1 \alpha$-cholecalciferol hydroxylase. ${ }^{6}$

PTH is considered to have mixed catabolic and anabolic effects on the skeleton. Long-standing hyperparathyroidism causes osteoporosis of predominantly cortical bone (forearm and hip), while it relatively preserves cancellous bone (spine). On the other hand, intermittent subcutaneous (sc) administration of low-dose PTH results in a skeletal anabolic response, more obvious in the cancellous than in the cortical bone, due to direct effects on cells of the osteoblastic lineage, and indirect effects through the regulation of selected skeletal growth factors. ${ }^{7}$ Although it appears that bone anabolic properties are fully maintained by the truncated fragment hPTH(1-31) or its cyclized lactam, the 34-amino acid peptide $\mathrm{hPTH}(1-34)$, teriparatide, is currently approved for the treatment of severe osteoporosis in the United States and Europe. ${ }^{4}$ Full-length PTH (PTH 1-84) is approved for the same indication only in Europe. Currently, PTH is the only proven bone anabolic therapy, whereas data attributing bone anabolic properties to classic antiresorptive agents, such as bisphosphonates ${ }^{8-10}$ or the strontium ranelate (originally considered as a mixed agent), ${ }^{3}$ are not consistently replicated. ${ }^{11}$ Intermittent PTH administration exerts its effects via several molecular actions, ${ }^{7}$ including but not limited to prevention of osteoblast apoptosis, ${ }^{12}$ induction of IGF-1 synthesis, inhibition of sclerostin expression, ${ }^{13}$ activation of Wnt signaling, ${ }^{14}$ and induction of transcriptional factors, such as runx2. ${ }^{15}$ Intermittent PTH has been shown to increase (a) the osteoblast number and their activity, (b) the bone remodeling rate along with the amount of bone deposited in each remodeling cycle, (c) trabecular thickness and trabecular connectivity, and (d) cortical thickness and bone size. ${ }^{6}$ Thus, PTH increases not only bone mass but also bone quality by improving microarchitecture and geometry. ${ }^{5,16}$ This mode of action is different from that of antiresorptives, which mainly act by maintaining skeletal architecture and decelerating bone turnover.

\section{Evidence for the usefulness of PTH as anabolic therapy in osteoporosis}

Daily SC administration of 20 or $40 \mu \mathrm{g}$ of teriparatide over a median duration of 19 months was associated with a statistically significant reduction in vertebral and non-vertebral fractures in women with low bone mass. ${ }^{17}$ Since the higher dose scheme was associated with a similar effect on bone fragility but a significantly higher risk of adverse events (such as hypercalcemia and hypercalciuria), the $20 \mu \mathrm{g}$ dose per day, associated with a $65 \%$ reduction in radiographic vertebral fractures, was selected for commercial use. 
Daily SC administration of full-length PTH (1-84) over 18 months was associated with a statistically significant reduction in vertebral, but not in non-vertebral, fractures in women with postmenopausal osteoporosis. ${ }^{18}$ Differences in efficacy observed between PTH analogs may be largely explained by differences in baseline characteristics between trials in regard to age and prevalence of vertebral fractures. Differences in adverse events, favoring teriparatide, were also evident; again, enrollment criteria might have played a role. Teriparatide could also be considered in the treatment of male osteoporosis ${ }^{19}$ as well as in glucocorticoid-induced osteoporosis. ${ }^{20}$

Short-term side-effects of PTH treatment include dizziness, leg cramps, hypercalcemia and hypercalciuria. In the long term, a putative risk for osteosarcoma has been reported in rat models with long-term (near lifetime) administration of doses many times higher than the doses approved for humans. ${ }^{21,22} \mathrm{On}$ the basis of this observation, and in accordance with recent studies, ${ }^{23}$ treatment duration with PTH analogs should not exceed 24 months, although small series have recently been published with treatment up to 36 months. ${ }^{24}$ Their use should not be considered in patients with Paget's disease, prior skeletal irradiation, unexplained elevations of bone-specific alkaline phosphatase, and adolescents with open epiphyses. To date, there is no evidence of increased risk of osteosarcoma in humans with either of the two available PTH preparations. Another debatable issue is the effect of PTH treatment on the cortical bone; either no change or a decrease in bone mineral density (BMD) at cortical bone sites (radius) has been reported with PTH treatment. ${ }^{17,25}$ These changes may be attributed to a decrease in secondary mineralization of newly formed osteoid and are probably counteracted by an increase in cortical bone diameter (since the strength of a cylinder is proportional to the fourth power of its radius). This "paradox" may be indicative of the suboptimal estimation of bone strength and integrity only on the basis of areal bone mass measurements, age, and prevalence of vertebral fractures.

\section{Comments}

Although new bone formation with PTH therapy could be regarded as the "holy grail" in osteoporosis treatment, certain parameters, associated with
PTH therapy, may attenuate the optimism. First, an "anabolic window" is observed with PTH treatment, namely increases in bone-formation markers are followed by analogous increases in bone-resorption markers, ${ }^{26}$ and thus coupling occurs and a new balance is established. Second, PTH is a last resort therapy ${ }^{6}$ since its maximal use does not exceed 24 months in a lifetime, whereas treatment of osteoporosis far exceeds this time frame. Third, it is an expensive treatment and is recommended as an alternative treatment option for the secondary prevention of fractures only in postmenopausal women who are (a) 65 years or older and have a T-score $\leq-4.0 \mathrm{SD}$, or a T-score $\leq-3.5 \mathrm{SD}$ plus more than two fractures, or who are aged 55-64 years and have a T-score $\leq-4$ SD plus more than two fractures and (b) intolerant of oral bisphosphonates and strontium ranelate (http: //guidance.nice.org.uk/TA161/Guidance). Furthermore, hard evidence on hip fracture reduction is still lacking for both preparations. Moreover, adherence and persistence to daily injections seem to decline after the first 6-month period, ${ }^{27}$ a parameter which may undermine treatment efficacy. There is also a need for resolution-of-effect data, namely evidence on what happens when treatment is discontinued. ${ }^{28}$ Finally, patients may be reluctant to initiate a therapy that requires daily injections.

\section{Novel PTH preparations}

In an attempt to overcome the compliance issues, alternative methods of PTH administration (oral, transdermal, nasal) have been tested. PTH (1-34) was formulated with the absorption enhancer 5-CNAC to provide an oral PTH preparation, named PTH134. In a Phase I, single-center, partially blinded, incomplete cross-over trial (NCT00676312) reported in 2009 at the ACR/ARHP Annual Scientific Meeting (DOI: 10.1002/art.25967), PTH134, at doses of 2.5 or $5 \mathrm{mg}$, provided systemic exposure levels approximating those of teriparatide $20 \mu \mathrm{g} \mathrm{SC}$ showed a comparable incidence of adverse events in 32 healthy postmenopausal women. Another study of similar design in osteoporotic/osteopenic postmenopausal women, using bone markers as the main outcome measure, is currently recruiting (NCT01224717). Research regarding transdermal PTH delivery is at a more advanced stage. PTH transdermal patch is composed of a small adhesive patch coated with PTH (1-34) 
(TPTD-P). ${ }^{29}$ In a 6-month, randomized, placebocontrolled trial (RCT) in 165 postmenopausal women, TPTD-P (20, 30 or $40 \mu \mathrm{g}$ dose) significantly increased total hip BMD compared to both placebo patch and teriparatide injection and lumbar spine (LS) BMD vs placebo patch in a dose-dependent manner. ${ }^{30}$ A nasal spray formula of PTH (1-34) provided encouraging results in a 3-month, uncontrolled, open-label pilot study in 90 osteoporotic subjects using LSBMD as the main outcome measure. ${ }^{31}$ However, the subsequent, Phase II, 6-month, active-controlled trial was terminated prior to enrollment for unknown reasons (NCT00624481).

Aside from alternative routes of PTH administration, different PTH analogs have been developed in an attempt to achieve a safer and more potent profile. ZT-031 (ostabolin-C) is a cyclic 31-amino acid PTH analog which when administered by daily SC injections to postmenopausal women with osteoporosis, resulted in a dose-dependent increase in LS and total hip (TH) BMD without significant adverse events. ${ }^{32}$ For all the above preparations, anti-fracture efficacy, safety, and tolerability should be documented before this treatment may be considered as alternative to standard therapy.

\section{PTH-RELATED PEPTIDE (PTHrP)}

\section{Background}

PTHrP acts as a paracrine regulator in several tissues, including cartilage, mammary, developing tooth, central nervous system, and smooth muscle..$^{33}$ It is also considered the most common cause of humoral hypercalcemia of malignancy. ${ }^{34}$ Although PTHrP and PTH are products of different genes, with sequence divergence at the amino acid and nucleotide level, limited overall sequence homology $(16 \%)$, and fundamentally differing physiology, they can activate a common G-protein coupled receptor, the PTH/PTHrP receptor (PTH1R) in their target cells, such as osteoblasts and renal tubular cells. ${ }^{35}$ This is explained by the significant homology in their $\mathrm{N}$-terminal, where nine out of their 13 amino acid residues are identical. Given the common receptor in the skeleton, it could be postulated that truncated PTHrP could exert actions similar to those of PTH.

\section{Evidence for potential usefulness of PTHrP as anabolic therapy in osteoporosis}

In preclinical models, PTHrP -/- mice died postnatally, probably from asphyxia, and exhibited widespread abnormalities of endochondral bone development. ${ }^{36} \mathrm{PTHrP}+/$ - mice by age 3 months presented with osteopenia characterized by altered trabecular architecture. ${ }^{37} \mathrm{In} \mathrm{PTHrP}+/$ - mice, daily administration of the 1-34 amino-terminal fragment of parathyroid hormone (PTH 1-34) resulted in profound improvement in all parameters of skeletal microarchitecture, ${ }^{38}$ establishing a role of PTHrP in bone formation in a PTH-like manner. In mice and rabbit models, the important role of PTHrP was documented in both endochondral and intramembranous bone formation. ${ }^{39}$ What's more, synthetic human PTHrP stimulated bone resorption and caused hypercalcemia in rats. ${ }^{40}$

In humans, daily SC PTHrP (1-36) produced reduction in serum phosphorus and the renal phosphorus reabsorption threshold, increments in fractional calcium excretion and nephrogenous cAMP excretion, and increases in plasma 1,25-dihydroxyvitamin D. ${ }^{41}$ Daily SC PTHrP (1-36) administration for 14 days in 13 postmenopausal women provided evidence of uncoupling bone formation from resorption, as assessed by relevant markers. ${ }^{42}$ In a 3 -month double-blind $\mathrm{RCT}, 16$ postmenopausal women with osteoporosis were administered daily SC PTHrP $(6.56 \mathrm{mcg} / \mathrm{kg} / \mathrm{d}$, or approximately $400 \mu \mathrm{g}$ daily), along with calcium and vitamin D. The PTHrP group displayed a $4.7 \%$ increase in LS BMD, an increase in serum osteocalcin, and no change in markers of osteoclastic bone resorption. ${ }^{43}$ In a dose escalation study in healthy volunteers, SC PTHrP (1-36) was found safe in single doses up to $2.0 \mathrm{mg} .^{44}$ In a subsequent 3 -week dose escalation clinical trial in 41 healthy postmenopausal women, PTHrP administration in the dose of 500 and $625 \mu \mathrm{g}$ daily was not associated with serious adverse events, whereas those on $750 \mu \mathrm{g}$ developed mild hypercalcemia, attributed to activation of intestinal calcium absorption by 1,25 dihydroxyvitamin $\mathrm{D}$ and not to activation of bone resorption. ${ }^{45} \mathrm{~A} 3$-month, comparison trial of PTH (1-34) and two different doses of PTHrP (1-36) is currently recruiting postmenopausal women with osteoporosis to assess the stimulation of bone formation in relation to bone resorption (NCT00853723). 


\section{Comments}

PTH is considered as a mixed skeletal anabolic and catabolic agent and its use has been limited by nausea, muscle cramping, and hypercalcemia. ${ }^{45}$ The latter is associated with increases in osteoclast-driven bone resorption. Thus, an agent that preferably stimulates bone formation over bone resorption might circumvent these problems. ${ }^{45}$ However, although PTHrP did not result in increased bone resorption markers in human studies, it is quite possible that this effect was caused by the limited period of administration, which could probably correspond to the "anabolic window" of PTH treatment. On the other hand, evidence regarding PTHrP anti-fracture efficacy is still lacking and SC administration does not address the major issue of convenience of treatment in order to maximize compliance.

\section{CALCILYTICS}

\section{Background}

The secretion of PTH by the parathyroid glands is tightly regulated by a $G$ protein-coupled receptor (GPCR), the calcium-sensing receptor (CaSR). In humans, loss-of-function CaSR mutations are associated with autosomal dominant familial hypocalciuric hypercalcemia $(\mathrm{FHH})$, whereas gain-of-function mutations are associated with autosomal dominant hypocalcemia $(\mathrm{ADH}){ }^{46}$

CaSR is highly expressed in the chief cells of the parathyroid gland where it is involved in the regulation of PTH gene-expression, PTH secretion, and parathyroid gland hyperplasia. ${ }^{47} \mathrm{CaSR}$ activation by extracellular $\mathrm{Ca}^{2+}$ leads to inhibition of PTH secretion. ${ }^{48}$ Antagonism of the CaSR would mimic a state of hypocalcemia and elicit a PTH pulse as a compensatory mechanism. ${ }^{49}$ Given that intermittent rather than continuous PTH exposure promotes anabolic rather than catabolic effect on the skeleton, it has been suggested that transient, short-acting antagonists of the CaSR, resulting in transient, rapid bursts in PTH, would favor new bone formation, mimicking intermittent PTH administration. The negative allosteric modulators of the CaSR, which right-shift the concentration-response curve of $\mathrm{Ca}^{2+}$, are known as calcilytics. Of note, an orthosteric antagonist of the CaSR has not yet been identified. ${ }^{50}$

\section{Evidence for potential usefulness of calcilytics as anabolic therapy in osteoporosis}

In preclinical models, several oral compounds with CaSR antagonizing properties, including NPS 2143, Calhex 231, and SB-423557, have been tested for their efficacy to stimulate a PTH "spike" and increase bone formation in ovariectomized rats. ${ }^{48,49,51,52}$ A structure similar to NPS 2143, ronacaleret hydrochloride, demonstrated a convenient pharmacokinetic profile and reached Phase II to assess its safety and efficacy. ${ }^{53}$ In this 12-month, double-blind, placebo and activecontrolled (alendronate and teriparatide) trial, efficacy of ronacaleret hydrochloride $(100,200,300,400 \mathrm{mg}$ daily) was assessed using surrogate markers of antifracture efficacy (LS and TH BMD, bone turnover markers, bone-strength parameters). However, that trial and further development were terminated due to lack of efficacy, which was attributed to a variety of factors such as poor exposure, limited ability of dose escalation due to safety concerns or lack of potency ${ }^{54}$ Recently, a follow-up observational study (CR9112792) after ronacaleret discontinuation was completed. This study used the percent change in LS BMD measured by dual x-ray absorptiometry (DXA) as the primary outcome and the results are to be published.

Most recently, two novel structural classes of oral calcilytics were reported. Both of them showed a favorable pharmacokinetic profile of PTH stimulation in osteopenic ovariectomized rats ${ }^{55,56}$ and dogs. ${ }^{56}$

\section{Comments}

The most appealing characteristics of the calcilytics are (1) the oral administration, which circumvents the major problem of consistency and adherence to daily injections of PTH, and (2) the stimulation of the natural PTH, as opposed to teriparatide or synthetic PTH 1-84. However, it should be noted that CaSR is expressed in other tissues, such as kidney, bone cells, ${ }^{57}$ heart. ${ }^{58}$ In fact, it has been suggested that CaSR might be one of the mediators of strontium ranelate effects on bone cells..$^{59}$ At doses used for the antagonism of the parathyroid cell CaSR leading to "a dramatic increase in bone turnover", calcilytics do not interact with the bone cell CaSR.$^{49}$ However, this might not be the case for the heart cell CaSR, which is worrisome, especially in the light of new evidence 
suggesting that CaSR antagonism in the heart may impair cardioprotective ischemic preconditioning. ${ }^{58}$

\section{BETA-BLOCKERS}

\section{Background}

Bone is innervated by, autonomous nervous system and osteoblasts express the beta- 2 adrenergic receptors (beta2AR). ${ }^{60}$ Evidence from mice models suggests a central regulation of bone mass by the sympathetic nervous system (SNS), mediated through leptin-regulated neural pathways. ${ }^{61,62}$ The exact mechanisms involved in this type of regulation of bone mass, involving norepinephrine, acetylcholine, leptin, neuropeptide $\mathrm{Y}$, neuromedin $\mathrm{U}$, endocannabinoids, and serotonin interactions, have not been fully elucidated as yet. In general, SNS activation is considered to contribute to bone loss.

Beta-Adrenergic receptor antagonists (beta-blockers - BB) are established antihypertensive agents and their actions result from a reduction in cardiac output and in renin activity and inhibition of the catecholamines peripheral action on beta-adrenergic receptors..$^{63}$ It appears that $\mathrm{BB}$ may also have a role in bone metabolism.

\section{Evidence for potential usefulness of BB as anabolic therapy in osteoporosis}

In preclinical models, deletion of one or both copies of the beta2AR increased bone mass in mice. ${ }^{61}$ Treatment with the low-dose agonist isoprenaline, a nonspecific beta-AR agonist, induced bone loss mainly via enhanced bone resorption in mice,${ }^{64}$ whereas lowdose propanolol, a non-selective $\mathrm{BB}$, increased bone formation in a rat model. ${ }^{65}$

In humans, the potential role of BB in osteoporosis has largely been based on retrospective database analysis. A large, registry-based, case-control study from the UK, which included 30,601 case subjects (defined as such with any incident fracture) and 120,819 appropriately matched controls, provided evidence that use of $\mathrm{BB}$ is associated with a reduced risk of fractures, either alone (OR: 0.77, CI 0.72-0.83) or in combination with thiazide diuretics. ${ }^{66}$ Using the same UK database, with the addition of the Dutch database and a different definition of cases (a first hip or femur fracture), researchers concluded that the use of BB was associated with a reduced risk of hip/ femur fracture in both (UK and Dutch) study populations (adjusted OR $=0.82,95 \%$ CI $0.74-0.91$, and adjusted OR $=0.87,95 \%$ CI 0.80-0.95, respectively). Moreover, the investigators concluded that this risk reduction was not associated with the cumulative dose or BB selectivity but with the past use of other antihypertensive agents. ${ }^{67}$ Subsequently, using the same Dutch database, but investigating the effect of beta-2 agonists instead of $\mathrm{BB}$, researchers found an association between higher doses of beta- 2 agonists and significant risk of hip/femur fracture, although this excess risk was substantially reduced after exclusion of oral glucocorticoid users and adjustment for the underlying disease. ${ }^{68}$ Accordingly, a relevant metaanalysis of seven observational studies associated the use of BB with a significant reduction of any type of fracture [Relative Risk $0.86,95 \%$ Confidence Interval (CI) $0.70-0.98] .{ }^{69}$ In a case-control study using as a reference population 944 postmenopausal women referred for BMD measurement, BB users had higher $\mathrm{BMD}$ and a borderline significantly lower risk for fractures at all sites (odds ratio 0.56; 95\% CI: 0.30$0.99) .{ }^{70}$ In a prospective, population-based study of 1,793 subjects with mean follow-up of around 11 years, the association between the use of $\mathrm{BB}$ and incidence of any fracture was significant after adjustment for a variety of potential effect modifiers [Hazard ratio $0.60 ; 95 \% \mathrm{CI}=0.37-0.96) .{ }^{71} \mathrm{In}$ a recent prospective cohort study of 3,488 individuals, the same association (use of BB associated with lower fracture risk) was confirmed and was found to be robust in selective over non-selective BB users and independent of sex, age, BMD, and clinical risk factors. ${ }^{72}$

\section{Comments}

The evidence on the effects of BB on the human skeleton is largely derived from observational studies which cannot establish a cause-effect relationship and hence further validation is required. Assumptions on the exact mechanism of their effect may be projected from preclinical models, favoring an anticatabolic over an anabolic action. In humans, evidence suggests that $\mathrm{BB}$ use is associated with significantly higher LS and FN BMD, higher cortical width, and higher mean $\mathrm{H}$ parameter, an index that reflects a better trabecular microarchitecture. ${ }^{70}$ Moreover, an elegant experiment in humans demonstrated a PTH burst as a response 
to selective beta- 1 adrenergic blockade by esmolol, ${ }^{73}$ mimicking the effects of CaSR antagonism. Despite these data, the role of BB in osteoporosis has not as yet been adequately elucidated.

\section{ENHANCEMENT OF WNT/B-CATENIN SIGNALING PATHWAY}

\section{Background}

Wnts (Wingless tail) or Wnt ligands constitute a family of secreted, lipid-modified, cysteine-rich glycoproteins which play an important role in the regulation of cell differentiation and proliferation. ${ }^{74}$ In osteoblasts, Wnt ligands can act either through the $\mathrm{Wnt} / \beta$-catenin canonical pathway or the non-canonical ( $\beta$-catenin independent) pathways. The latter include Wnt/planar cell polarity signaling, the Wnt-cGMP/ $\mathrm{Ca}^{2+}$ pathway, and a protein kinase A pathway but the net effect of their activation on bone metabolism remains to be elucidated. ${ }^{75}$ On the other hand, activation of the $\beta$-catenin dependent canonical pathway is considered to (i) promote osteoblast commitment from the multipotential, mesenchymal progenitors, (ii) stimulate osteoblast proliferation and differentiation at the expense of osteoclastogenesis, and (iii) prevent both osteoblast and osteocyte apoptosis. ${ }^{76}$ These actions render the Wnt/ $\beta$-catenin canonical pathway and its modulators a promising target for treating low-bone mass disorders. ${ }^{77}$

In brief, cytoplasmic $\beta$-catenin levels are normally kept low through continuous degradation. ${ }^{78}$ In the absence of Wnt ligands, $\beta$-catenin is phosphorylated by kinases, forming the " $\beta$-catenin destruction complex", and is subsequently degradated. Glycogen synthase kinase-3 $\beta$ (GSK3 $\beta$ ) plays a major role in this complex along with the protein axin, the adenomatous polyposis coli (APC) protein, and the casein kinase 1 . Phosphorylated $\beta$-catenin is then ubiquitinated before final proteosomal degradation. ${ }^{79}$ In the presence of Wnt ligands (Wnt1, Wnt3A, Wnt8, Wnt10b), $\beta$-catenin degradation is inhibited, resulting in its accumulation in the cytoplasm and its translocation into the nucleus, where nuclear $\beta$-catenin interacts with $\mathrm{T}$ cell-specific transcription factor/lymphoid enhancer-binding factor 1 (TCF/LEF) to promote the transcriptional response of Wnt target genes. ${ }^{15}$ The cascade of events that leads to $\beta$-catenin stabilization in the cytoplasm is a receptor-mediated response in which Wnt ligands interact with a member of the Frizzled family (Fzd) and the co-receptor lipoprotein-receptor related protein (LRP) 5 or $6{ }^{80,81}$ The formation of a receptor complex (Wnt-Fzd and LRP5/6) results in inhibition of $\beta$-catenin phosphorylation by GSK-3 $\beta$ through an intracellular process that involves the cytoplasmic protein dishevelled (Dsh/Dvl) and axin. ${ }^{78}$

The Wnt/ß-catenin canonical pathway is modulated by a complex network of extracellular antagonists, transmembrane modulators or intracellular signals. ${ }^{82}$ In fact, it has been suggested that the "non-canonical" Wnts (Wnt4, Wnt5a, and Wnt11) may antagonize Wnt//-catenin signaling. ${ }^{83}$ In humans, known antagonists of the Wnt/ $\beta$-catenin canonical pathway include Wnt Inhibitory Factor 1 (WIF-1), secreted frizzled related proteins (sFRPs), Dickkopf (Dkk) proteins, and sclerostin. WIF-1 and sFRPs are extracellular proteins which bind directly to Wnt proteins, thus preventing them from activating the $\mathrm{Wnt} / \beta$-catenin canonical pathway. ${ }^{84} \mathrm{sFRPs}$ act as decoy receptors by mimicking Fzd structure. On the other hand, Dkks and sclerostin target LRP5/6 mediation of Wnt signaling. Dkks (Dkk1 and Dkk4, but not Dkk2) by binding to transmembrane Dkk receptors (Kremens proteins) and form a complex that attracts and internalizes LRP5/6, disrupting the Wnt/ $\beta$-catenin canonical pathway. ${ }^{85,86}$ Sclerostin, the product of the SOST gene, produced almost exclusively by osteocytes, binds to LRP5/6 domains and antagonizes LRP5/6-mediated Wnt signaling. ${ }^{87}$ The Wnt/ $\beta$-catenin canonical pathway, in its inactive and active form, is depicted in Figure 1.

Certain genetic disorders provide interesting insights into the effects of the enhancement or disruption of the $\mathrm{Wnt} / \beta$-catenin pathway in in vivo models. The osteoporosis-pseudoglioma syndrome (OPPG) is a rare autosomal recessive disorder of severe juvenile osteoporosis and congenital blindness due to lossof-function mutations in the LRP5 gene (disruption of Wnt $/ \beta$-catenin pathway). ${ }^{88,89} \mathrm{~A}$ single amino-acid substitution $(\mathrm{G} 171 \mathrm{~V})$ in the same gene, which prevents Dkk1 binding, leads to high bone mass disorders..$^{90,91}$ Six other amino-acid substitutions in the aminoterminal part of LRP5 protein also resulted in high bone mass phenotype. ${ }^{92}$ Similarly, a missense mutation in LRP6 leads to autosomal dominant early cardiovascular disease (CAD), hyperlipidemia, hyperten- 

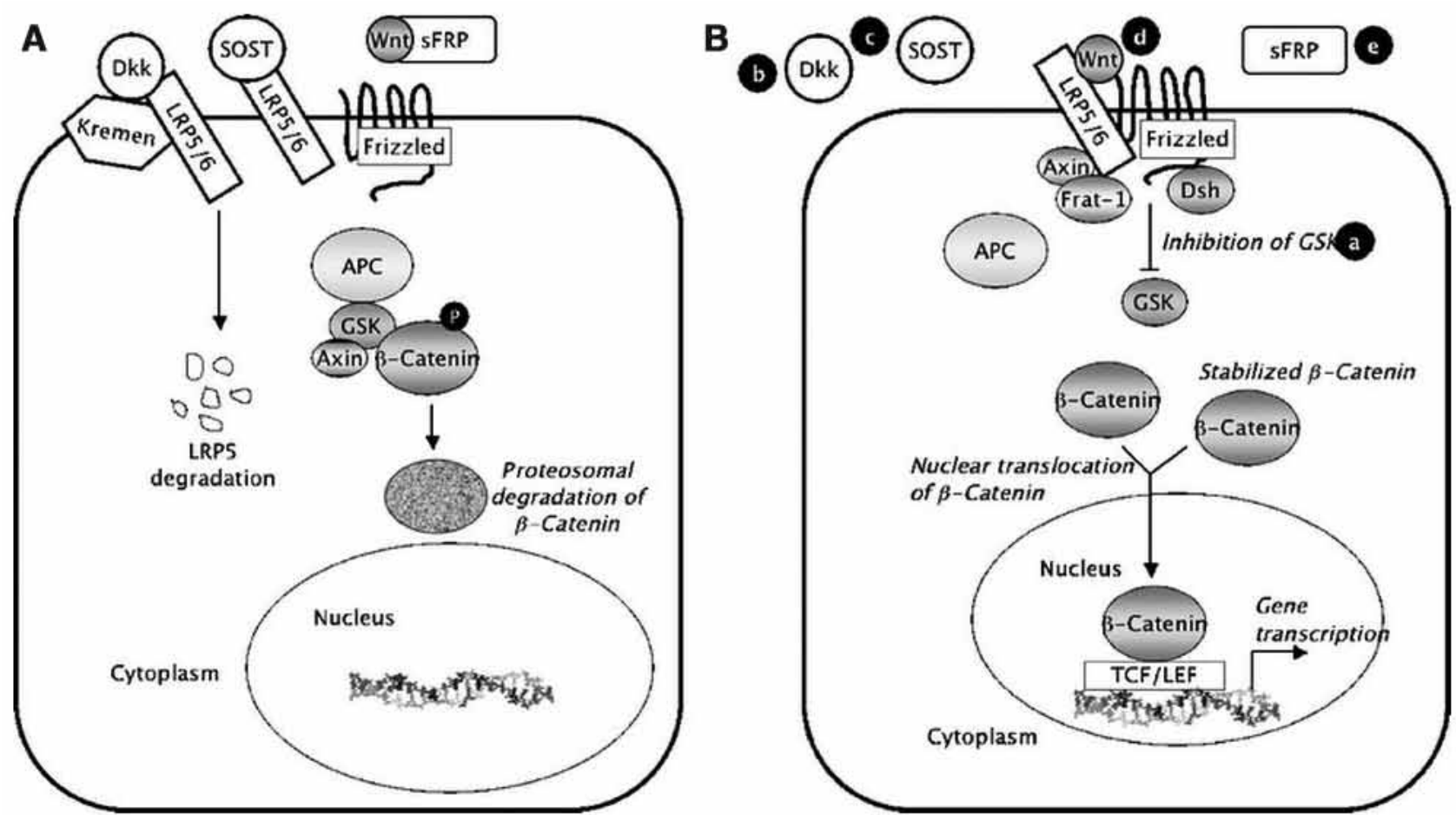

Figure 1. Overview of the Wnt signaling pathway in the inactive and active state. (A) Wnt signaling pathway in the inactive state, showing a ligand Wnt inhibited by a decoy secreted frizzled-related protein (sFRP), the co-receptor, low-density lipoprotein receptor-related protein (LRP) 5/6, bound by either inhibitory protein, sclerostin or Dkk (Dickkopf), and Glycogen synthase kinase (GSK)-3 $\beta$ in the active state, resulting in proteosomal degradation of $\beta$-catenin. (B) Active Wnt signaling, with LRP5/6 engaging in receptor complex after Wnt binding, disruption of GSK-3 $\beta$ inhibitory complex, stabilisation of $\beta$-catenin, and its translocation to nucleus where it activates transcription. Reproduced with kind permission from Springer Science + Business Media: Osteoporosis International, regulatory pathways revealing new approaches to the development of anabolic drugs for osteoporosis, 19: 2008, pp. 1125-38, Martin TJ, Sims NA, Ng KW, Figure 2.

sion, diabetes, which and osteoporosis (disruption of $\mathrm{Wnt} / \beta$-catenin pathway).$^{93}$ Sclerosteosis and van Buchem disease, which are rare sclerosing bone dysplasias caused by inactivating mutations in the SOST gene ${ }^{94,95}$ and deletion in regulatory elements of SOST transcription, ${ }^{96}$ respectively, result in absence of sclerostin expression and progressive generalized osteosclerosis. Patients with sclerosteosis have a more severe phenotype compared to patients with van Buchem disease and usually have syndactyly, ${ }^{97}$ while the gene carriers have increased BMD.

\section{Evidence for potential usefulness of Wnt/B- catenin pathway components as anabolic therapy in osteoporosis}

Several components of the $\mathrm{Wnt} / \beta$-catenin pathway could be potential targets for osteoanabolic treatment (Figure 1B). Those at the most advanced stage of development, namely sclerostin neutralization, Dkk1 neutralization, and GSK-3 $\beta$ inhibition, will be reviewed herein.

In in vivo models investigating sclerostin neutralization, 5-week treatment with a sclerostin neutralizing monoclonal antibody (Scl-AbII) increased bone formation at all sites in aged ovariectomized rats, ${ }^{98}$ aged male rats ${ }^{99}$ and primates (cynomolgus monkeys). ${ }^{100}$ Two sclerostin monoclonal antibodies (Mabs) (AMG 785 and AMG167) have been developed and are currently under investigation in humans. In a 3-month, phase I, double-blind RCT, 72 healthy men and postmenopausal women were subjected to a single injection of either AMG 785 or placebo in a 3:1 ratio. ${ }^{101}$ AMG 785 was administered SC $(n=42)$ or intravenously $(n=12)$ in sequentially increasing dosages and was generally well tolerated. A dose-dependent increase in LS and TH BMD and 
in bone formation markers (P1NP, osteocalcin, bone specific ALP) was observed. The largest increase in LS $(5.3 \%)$ and TH $(2.8 \%)$ BMD at 3 months was observed with the highest SC dose of $10 \mathrm{mg} / \mathrm{kg}$. In the same cohort, over two-fold increase in bone formation markers at 3-4 weeks and a sustained reduction of approximately $50 \%$ in serum C-terminal type 1 collagen telopeptide (sCTX) were observed. Of note, no subjects received calcium or Vit D supplementation, which may have resulted in underestimation of AMG 785 efficacy. ${ }^{101}$ The magnitude and pattern of changes in bone markers implies a rapid uncoupling of bone formation - resorption and possibly a prolonged "anabolic window". ${ }^{102}$ A Phase I trial of similar design is currently ongoing in a healthy Japanese population (NCT01101061). On the basis of these findings and the pharmacokinetic/pharmacodynamic (PKPD) profile assessed in the Phase I trial, SC administration at 4 weeks intervals and doses of 70, 140, and $210 \mathrm{mg}$ have been selected for further investigation in a Phase II trial. A 12-month RCT (NCT00896532) was designed, using a sample size of 419 postmenopausal women with low BMD, percent change from baseline at month 12 in LS BMD as the primary outcome and placebo, alendronate, and teriparatide as comparators. Furthermore, a sclerostin antibody (Scl-AbIII) increased bone formation during metaphyseal repair, but also in untraumatized bone in rats. ${ }^{103}$ Therefore, AMG 785 is currently under investigation for its efficacy in functional healing in patients with intertrochanteric fractures of the proximal femur (NCT01081678), in radiographic fracture healing in patients with tibial diaphyseal fractures (NCT 00907296), and for its effect on the bone quality of the forearm in postmenopausal women with low bone mass (NCT00950950). As for AMG 167, a Phase I, ascending single-dose, doubleblind RCT to evaluate its safety, tolerability, and PKPD in healthy men and postmenopausal women has been completed (NCT00902356). This study is being followed by another Phase I, multi-dose trial in men and postmenopausal women with low BMD and no history of fragility fracture, which is currently ongoing (NCT01101048) and will include calcium and Vit D supplementation.

Four to six week treatment with an anti-Dkk1 antibody increased BMD and the number of osteoblasts in a mouse model of multiple myeloma. ${ }^{104}$ In humans, an investigational anti-Dkk1 antibody (PF-04840082) has been developed. In elegant preclinical PKPD profiling experiments, intravenous PF-04840082 lowered Dkk-1 levels in a dose-dependent manner and it was estimated that $0.008 \mathrm{mg} / \mathrm{kg} /$ day, could be the starting dose with the minimal biological effect in humans. ${ }^{105}$ A 3-month Phase I study to evaluate the safety, tolerability, immunogenicity, and PKPD of escalating doses of IV RN564 in women with osteopenia and in healthy men has been announced (NCT01293487); percentage changes from baseline in $\mathrm{LS}, \mathrm{TH}, \mathrm{FN}$, and distal radius BMD at Day 85 are included as a secondary outcome.

In in vivo models investigating GSK-3 $\beta$ neutralization, 4 weeks of treatment with the GSK-3 $\beta$ inhibitor, lithium chloride, resulted in increased bone formation and bone mass in Lrp5(-/-) mice. ${ }^{106}$ Treatment with an oral dual GSK-3a and -3b inhibitor (LY603281 $31-8$ ) for 2 months resulted in increased markers of bone formation, bone mass, and strength in ovariectomized rats. ${ }^{107}$ Given the involvement of GSK-3 in significant signaling pathways, the probable lack of tissue specificity in GSK-3 $\beta$ inhibition and sideeffects associated with lithium, the development of a GSK-3 $\beta$ inhibitor for osteoporosis treatment in humans seems difficult at present. . $^{14,15}$

An alternative means of $\mathrm{Wnt} / \beta$-catenin pathway activation, involving antagonism of sFRP-1, has recently been reported in in vitro experiments in which diarylsulfone sulfonamide (WAY-316606), by binding to sFRP-1, increased total bone area in murine cultures. ${ }^{108}$

\section{Comments}

Safety and tissue specificity are the prerequisites and key goals in the development of any treatment, especially when addressing a chronic condition such as osteoporosis. Indirect evidence from clinical observation and basic data suggest that both of them (safety and tissue specificity) may be anticipated in sclerostin neutralization. In fact, patients with sclerosteosis and van Buchem disease, where sclerostin is absent, live a fairly normal life, with the exception of skeletal manifestations and those secondary to nerve compression (safety).$^{97}$ Furthermore, sclerostin is produced almost exclusively by osteocytes (tissue specificity). Thus, it comes as no surprise that the 
pharmaceutical neutralization of sclerostin is actively sought for and currently at the most advanced stage of development among all candidate molecules targeting $\mathrm{Wnt} / \beta$-catenin pathway.

\section{PERIPHERALLY DERIVED 5-HYDROXYTRYPTAMIN (HT)}

\section{Background}

Serotonin or 5-HT is derived from tryptophan and is found either in the periphery (gastrointestinal tract, platelets) or in the central nervous system, exhibiting distinct functions, depending on the site. Peripheral 5-HT is synthesized in enterochromaffin cells of the gut, with an isoform of tryptophan hydroxylase (Tph1) playing the role of rate limiting enzyme, and then stored in platelets. Brainstem-derived 5-HT (BDS) is synthesized locally under the control of another isoform of Tph (Tph2); the bloodbrain barrier does not allow 5-HT to cross in either direction, thus allowing them to act in relative isolation. ${ }^{109} 5$-HT has recently attracted great interest in bone biology after experimental data suggesting that it could be part of a novel endocrine axis regulating bone mass, and consequent therapeutic implications. ${ }^{110}$ Experiments using conditional gene deletion and microarray in mice demonstrated that LRP5, the alleged co-receptor in the $\mathrm{Wnt} / \beta$-catenin pathway, may promote bone anabolism in a Wnt-independent manner by inhibiting the expression of Tph1 in the duodenum. ${ }^{11}$ Furthermore, BDS favors bone mass accrual after its binding to medial hypothalamic neurons and this bone anabolic action is inhibited by leptin, providing a link between central regulation of bone mass, energy expenditure, and appetite. ${ }^{112}$ However, recently published experiments by another laboratory failed to replicate these findings. ${ }^{113}$

\section{Evidence for potential usefulness of 5-HT as anabolic therapy in osteoporosis}

In preclinical models, a decrease in 5-HT blood levels with an inhibitor of 5-HT synthesis (parachlorophenylalanine) or a low-tryptophan diet resulted in normalization of bone formation and bone mass in Lrp5-deficient mice. Gut- but not osteoblast-specific Lrp5 inactivation resulted in a decrease in bone formation. What's more, inactivation of Tph1 or gut-specific activation of Lrp5 prevented ovariectomy-induced bone loss and increased bone mass. ${ }^{114}$ Similarly, an oral inhibitor of both Tph-1 and Tph-2, LP533401, which decreases peripheral 5-HT levels, when administered to ovariectomized rodents for up to 6 weeks increased bone formation only and the subsequent increase in bone mass was dose-dependent. ${ }^{115}$ In addition, LP533401 was as effective as PTH in preventing the bone microarchitectural changes after ovariectomy. ${ }^{115}$ However, another laboratory reported no significant difference either in bone mass between Tph1-/- and wild type mice or in bone mass of ovariectomized mice after treatment with LP923941(Tph-1 inhibitor). ${ }^{113}$ Finally, fluoxetine (a selective serotonin reuptake inhibitor - SSRI), when administered to animal models, negatively affected bone accrual by reducing bone formation without increasing bone resorption; ${ }^{116}$ no significant effects in bone quality were observed after 6-month exposure. ${ }^{117}$

In humans, indirect evidence of the effect of 5-HT on the skeleton was sought in cross-sectional, casecontrol and prospective cohort studies, using BMD and fractures as outcome measures. However, different methodology applied for the measurement of 5-HT, the direct effect of medication on the sense of balance (a risk factor for falls), and other confounding factors suggest caution in the interpretation of the results. Although in cross-sectional analysis of NHANES III (7,114 male and 7,532 female participants) and of Women's Health Initiative Observational Study (82,410 women) antidepressants (including SSRI) were not associated with a significantly reduced BMD, ${ }^{118,119}$ several other studies reported the opposite in either gender. ${ }^{120-122}$ Several studies of variable design reported a significantly increased dose-specific risk of fractures associated with the use of SSRIs, ${ }^{119,121,123-128}$ with discordant results in regard to skeleton site. Finally, a recent population-based observational study suggested that in women, serum (but not platelet-poor plasma) 5-HT levels were weakly inversely correlated with indices of bone strength, as assessed by DXA, quantitative computed tomography (QCT), and highresolution peripheral QCT (pQCT). ${ }^{129}$

\section{Comments}

Recent evidence suggested a dual nature of 5-HT activity depending on the site of synthesis (central vs. peripheral); according to this, peripheral 5-HT has 
a negative effect on bone mass, whereas BDS has a positive effect. These findings were not replicated in recent experiments ${ }^{113}$ and hence more data are needed before considering peripherally derived 5-HT as a potential target for the development of novel anabolic agents.

\section{ACTIVIN ANTAGONIZING AGENTS}

\section{Background}

Activins are produced by pituitary cells and gonads and stimulate pituitary FSH release, while inhibins prevent activins from binding to their receptor type IIA (ActRIIA) in the gonadothophs, thereby suppressing FSH release; follistatin, another regulator of the system, binds and neutralizes activin. Activin, inhibin, and follistatin are members of the TGF-b superfamily. ${ }^{130}$ Age-related reduction in inhibin B and follistatin levels, subsequent increase in $\mathrm{FSH}$, and sustained levels of activin A have been implicated in the pathogenesis of fast bone loss in perimenopausal women. ${ }^{131,132}$

Activin A is expressed in bone, is abundant in the extracellular bone matrix, and seems to regulate both osteoblastogenesis and osteoclastogenesis. ${ }^{133}$ Its role in osteoblastogenesis is somewhat controversial. Activin A enhances the induction of ectopic bone formation when implanted concurrently with bone morphogenetic proteins (BMPs) ${ }_{134}$ increases osteoblast proliferation and collagen synthesis, ${ }^{135}$ increases the thickness of periosteum and bone matrix layers when injected into the periosteum, ${ }^{136}$ and stimulates fracture healing ${ }^{137}$ in animal models. By contrast, several studies demonstrated an inhibitory effect of activin A on osteoblast differentiation in murine, rat, and human cell cultures in vitro. ${ }^{138-140}$

On the other hand, activin A seems to exert a stimulatory effect in osteoclastogenesis and increases bone resorption via ActRIIA signaling; ${ }^{141-143}$ this could also result indirectly through stimulation of FSH release, which appears to promote osteoclastogenesis as well. ${ }^{144,145}$ In contrast, inhibins inhibit osteoclastogenic differentiation in bone marrow cultures, ${ }^{141}$ while they increase osteoblast differentiation in mice bearing the human inhibin A gene. ${ }^{133}$ Therefore, pharmacological blockage of activin signaling has been proposed as a target for the treatment of osteoporosis.

\section{Evidence for potential usefulness of activin antagonizing agents as anabolic therapy in osteoporosis}

Activin antagonists represent molecules that bind to activin and prevent it from binding to its endogenous receptor.

In preclinical models, a fusion protein of the extracellular domain of the ActRIIA linked to the Fc portion of murine IgG2a (RAP-011) stimulated bone formation, resulting in increased bone mass and strength in intact and ovariectomized mice. ${ }^{146} \mathrm{~A}$ similar soluble chimeric form of activin receptor type IIB (ActRIIB) fused to a murine IgG2aFc subunit was also tested and prevented loss of bone mass in gonadectomized male mice as assessed by whole body DXA and micro-computed tomography of proximal tibias. ${ }^{143}$ Another fusion protein of the extracellular domain of the ActRIIA linked to human IgG1-Fc (sotatercept - ACE-011) has also been developed. Within only 3 months, biweekly subcutaneous ACE011 at a dose of $10 \mathrm{mg} / \mathrm{kg}$ in primates increased bone mass by $13-15 \%$ and trabecular bone volume over $70 \% .{ }^{146}$ In another study in primates, ACE-011 increased bone formation rate and osteoblast surface and decreased osteoclast surface and number at all sites (vertebrae, femoral neck, and distal femur), indicating a dual model of action on the skeleton. ${ }^{147}$

In healthy postmenopausal women, a single-dose of ACE-011 (0.01-3.0 mg/kg IV and 0.03-0.1 mg/ $\mathrm{kg}$ s.c.) dose-dependently decreased FSH levels, increased serum bone-specific alkaline phosphatase (bone formation), and decreased levels of CTx and tartrate-resistant acid phosphatase (TRACP)-5b (bone resorption). ${ }^{148}$ ACE-011 was well tolerated.

\section{Comments}

To date, the efficacy of all available osteoporosis treatments (both anabolics and antiresorptives) is limited by the coupling effect. The dissociation between bone formation and resorption in favor of the former would lead to rapid and more significant bone mass increases. Activin antagonist ACE-011 is an agent with proven uncoupling effect in humans in that it increases bone formation while decreasing bone resorption. This may eventually mark a new class of agents in osteoporosis treatment, provided that this effect is verified in larger studies. 


\section{BONE MORPHOGENETIC PROTEINS}

Osteoblasts have receptors for BMPs which are, like activin $\mathrm{A}$, members of transforming growth factor- $\beta$ superfamily. BMP synthesis is not limited to bone and BMPs are expressed by a variety of extraskeletal tissues, where they play a critical role in organ development and cell function. BMPs were originally identified because of their ability to induce endochondral bone formation. ${ }^{149}$ BMPs induce the differentiation of mesenchymal stem cells (MSCs) toward cells of the osteoblastic lineage, increasing the pool of mature osteoblasts and enhancing their differentiation. Furthermore, BMPs induce endochondral ossification and chondrogenesis. ${ }^{150}$ BMPs also induce the transcription of osteoprotegerin, a decoy receptor that limits the effect of receptor activator of nuclear factor- $x \mathrm{~B}$-ligand (RANKL) on osteoclastogenesis. ${ }^{149}$ BMP-2, BMP-4, and BMP-6 are the most readily detectable BMPs in osteoblast cultures. However, there are exceptions: BMP-1 is a metalloprotease whose action is unrelated to other BMPs. ${ }^{150}$ In contrast, BMP-3 or osteogenin inhibits osteoblastogenesis. ${ }^{151}$

BMPs act through a cell membrane receptor complex. BMP binding to either the ActR2 dimer or BMP receptor type 2 (BMPR2) induces co-association of Activin receptor type 1 (ActR1) dimer. This results in a conformational change that enables Smad-1, Smad-5, and Smad- 8 proteins to bind Smad-4, and the whole Smad-complex to enter the nucleus to drive gene transcription. ${ }^{152}$ Apart from Smad activation, BMP receptor complex may also regulate gene transcription through mitogen-activated protein kinase (MAPK) activation. Extracellular antagonists, including noggin, gremlin, and twisted gastrulation, bind BMPs or components of the BMP signaling pathways and prevent their signal transduction. The antagonists are regulated by BMPs, indicating the existence and need for local feedback mechanisms to temper BMP cellular activities, given that unopposed BMP effects may be detrimental. ${ }^{149}$ It has also been proposed that BMP signaling induces sclerostin expression, thereby sclerostin is included in feedback mechanisms to self-limit BMP-induced excessive bone formation. ${ }^{153}$

\section{Evidence for potential usefulness of BMPs as anabolic therapy in osteoporosis}

BMPs play an important role in the advancement of bone engineering strategies. They have been used in the management of acute fracture, delayed fracture healing, arthrodesis, spinal fusion, and nonunion. Specifically, recombinant human (rh)BMP-2 and rhBMP-7 have been approved in several countries for specific indications, previously reviewed. ${ }^{154,155}$ The theoretical basis of local or systemic treatment of osteoporotic fractures with BMPs includes the rapid increase in bone strength locally at the fractured area or their action on the entire skeleton, when given systemically, as well as their acceleration of the bone-healing period. ${ }^{156}$

In preclinical models of osteoporosis, BMP-2, BMP-4, BMP-6, and BMP-7 have mainly been studied. rhBMP-2 induced bone formation in rat models, but its effect declined with age. ${ }^{157}$ In a mouse model, ${ }^{158}$ rhBMP-2 induced bone formation; the observed bone mass increase was associated with an increase in MSCs numbers, osteogenic activity and proliferation, and a decrease in apoptosis. Similarly, systemically administered ${ }^{125}$ I-BMP-6 increased bone volume and mechanical characteristics of both the trabecular and cortical bone, thereby improving microarchitecture and quality of the skeleton in osteoporotic rats. ${ }^{159}$ Locally applied rhBMP-7 treatment improved mechanical strength and histomorphometric parameters of osteopenic vertebra in an ovine model; however, these changes were not consistently associated with changes in BMD. ${ }^{160}$ Finally, ex-vivo gene therapy to deliver BMP-4 improved bone healing in critically sized fractures of osteoporotic rats. ${ }^{161}$

Apart from direct BMP administration, BMP indirect upregulation may represent promising targets. Osthole, a coumarin-like derivative extracted from Chinese herbs, has been shown to stimulate osteoblast proliferation and differentiation by both activating $\mathrm{Wnt} / \beta$-catenin signaling and increasing BMP-2 expression in a rat model of osteoporosis. ${ }^{162}$ Ursolic acid, derived from ubiquitous plant triterpenoid, was shown to have bone-forming activity in a mouse model, possibly through increasing BMP-2. ${ }^{163}$ 
Piceatannol, a polyphenol present in grapes and wine, increased BMP-2 synthesis, thereby inducing osteoblasts differentiation and increasing bone mass. ${ }^{164}$ Furthermore, naringin, a polymethoxylated flavonoid, was reported to increase BMP-2 expression and enhance osteogenesis. ${ }^{165}$

Other anabolic targets might be the inhibition of BMP antagonists' action. Silencing of noggin expression enhances new bone formation induced by rhBMP-2 in a mouse model, thereby proving useful for intensifying the effects of BMPs in promoting new bone formation. ${ }^{166}$ Similarly, deletion of gremlin gene resulted in sensitization of BMP signaling and activity and in enhancement of bone formation in mice. ${ }^{167}$

\section{Comments}

Despite favorable preclinical data and clinical data from orthopedic surgery, there are no clinical studies reporting the effect of recombinant BMPs administration or inhibitors of BMP antagonists in patients with osteoporosis. One Phase II clinical trial, comparing the effect of locally administered recombinant BMP-2 plus bisphosphonate versus bisphosphonate alone on BMD in postmenopausal women with low bone mass and high risk for hip fracture, is currently ongoing (ClinicalTrials.gov Identifier: NCT00752557).

Adverse events of BMP administration are reported in orthopedic studies. The reported data are limited and include mainly heterotopic ossification, but also minor immunogenic reactions, swelling, and infections. ${ }^{168}$ However, given that BMPs are critical for the differentiation and function of many cellular systems besides the skeleton, rhBMP administration or inactivation of BMP antagonists might be lethal or result in severe developmental abnormalities. ${ }^{149}$

It is expected that BMPs will be more intensively investigated in the preclinical and clinical setting of osteoporosis in the near future. Apart from cost and safety considerations, a technical problem that should be solved before integrating BMPs into the active osteoporosis research is the need for systemic administration. The majority of clinical orthopedic studies are performed with locally acting injections of BMPs on the site of fracture or fusion or nonunion and, therefore, are not directly applicable to osteoporosis, since osteoporosis is a systemic generalized rather than local metabolic disease. Therefore, the discovery of specific BMP-carriers would be of major importance for BMP-focused clinical trials. Silk fibroin microparticles have been used as carriers of rhBMP-2 in a rat model ${ }^{169}$ or poly-L-glycolic acid biospheres for rhBMP-7 in an ovine model ${ }^{160}$ with considerable success.

\section{GROWTH HORMONE (GH) AND INSULIN GROWTH FACTOR-1 (IGF-1)}

\section{Background}

The GH-IGF-1 axis exerts a predominantly anabolic effect on the skeleton, with the increase in bone formation surpassing the increase in bone resorption. ${ }^{170}$ The declining activity of the GH-IGF-1 axis with advancing age may contribute to the decrease in bone mass that occurs with aging. ${ }^{171}$

\section{Evidence for potential usefulness of $\mathrm{GH}$ or IGF-1 as anabolic therapy in osteoporosis}

In vitro studies demonstrated that both $\mathrm{GH}$ and IGF-1 increase bone collagen, ${ }^{172}$ while IGF-1 additionally stimulates the synthesis of bone DNA and non-collagen proteins. ${ }^{173}$ Furthermore, both molecules stimulate bone growth and osteoblast activity in animals. ${ }^{174,175}$ In some ${ }^{176-178}$ but not all ${ }^{179}$ studies, BMD of the LS was somewhat lower in untreated patients with adult-onset GH deficiency compared with normal subjects. The degree of osteopenia appears to correlate directly to the degree of GH deficiency. However, the number and severity of other hormonal deficiencies are also more pronounced in patients with more severe $\mathrm{GH}$ deficiency, ${ }^{180}$ making it difficult to determine which factors are the most important in the development of osteopenia. In elderly women but not in men higher serum IGF-1 levels were associated with higher BMD. ${ }^{181}$

Administration of GH to GH-deficient men and women has resulted in improvement in BMD in some ${ }^{171,182}$ but not all studies. ${ }^{183,184}$ Most of these studies did not have a placebo control group and virtually all used GH doses that resulted in supraphysiologic serum $\mathrm{GH}$ concentrations. In three randomized trials, $\mathrm{GH}$ treatment increased spine BMD in men but not in women. ${ }^{182,185,186} \mathrm{In}$ non-GH deficient men and women with normal BMD, ${ }^{170,187}$ osteopenia ${ }^{188}$ or osteoporo- 
sis, ${ }^{189-191} \mathrm{GH}$ administration has yielded conflicting results, whereas side-effects, such as hyperglycemia, hypertension, arthralgia, and the carpal tunnel syndrome, were common. ${ }^{171,187-191}$ These results plus the inconvenience of administration by daily injection rendered GH treatment unsuitable for patients with osteoporosis who are not GH-deficient. On the other hand, IGF-1 therapy appeared to be ineffective. ${ }^{192}$

\section{Comments}

Osteoblasts have IGF-1 receptors and direct or indirect (through GH administration) delivery of IGF1 in these cells could result in an anabolic effect on the skeleton. However, although locally acting IGF-1 seems to play a decisive role in bone formation and many of the above mentioned therapies, including PTH, may exert their action, at least in part, through induction of IGF-1 synthesis, ${ }^{193}$ there is no convincing evidence to date that SC GH or IGF-1 administration may constitute a promising osteoanabolic agent.

\section{CONCLUSION}

Targeting osteoblast could offer novel approaches for the improvement of bone strength and reversal of age-associated bone loss not currently addressed by the classic antiresorptive therapies. Since the approval of PTH use in the treatment of osteoporosis, recent advances in basic bone biology, including but not limited to the understanding of the Wnt/ $\beta$-catenin pathway, LRP5/osteoblast pathway, CaSR, PTHrP, and BMPs have revealed novel potential targets that could lead to the discovery of novel anabolic agents. An overview of these targets in the osteoblast and the osteoblast progenitor cell is illustrated in Figure 2. Among them, sclerostin neutralizing antibody, teriparatide transdermal patch, and PTHrP (1-36) seem to be at the most advanced stage of research (Table 1). Since osteoporosis is a chronic condition, safety and tissue specificity are prerequisites in the development of a novel treatment, especially when it affects molecular signaling pathways.

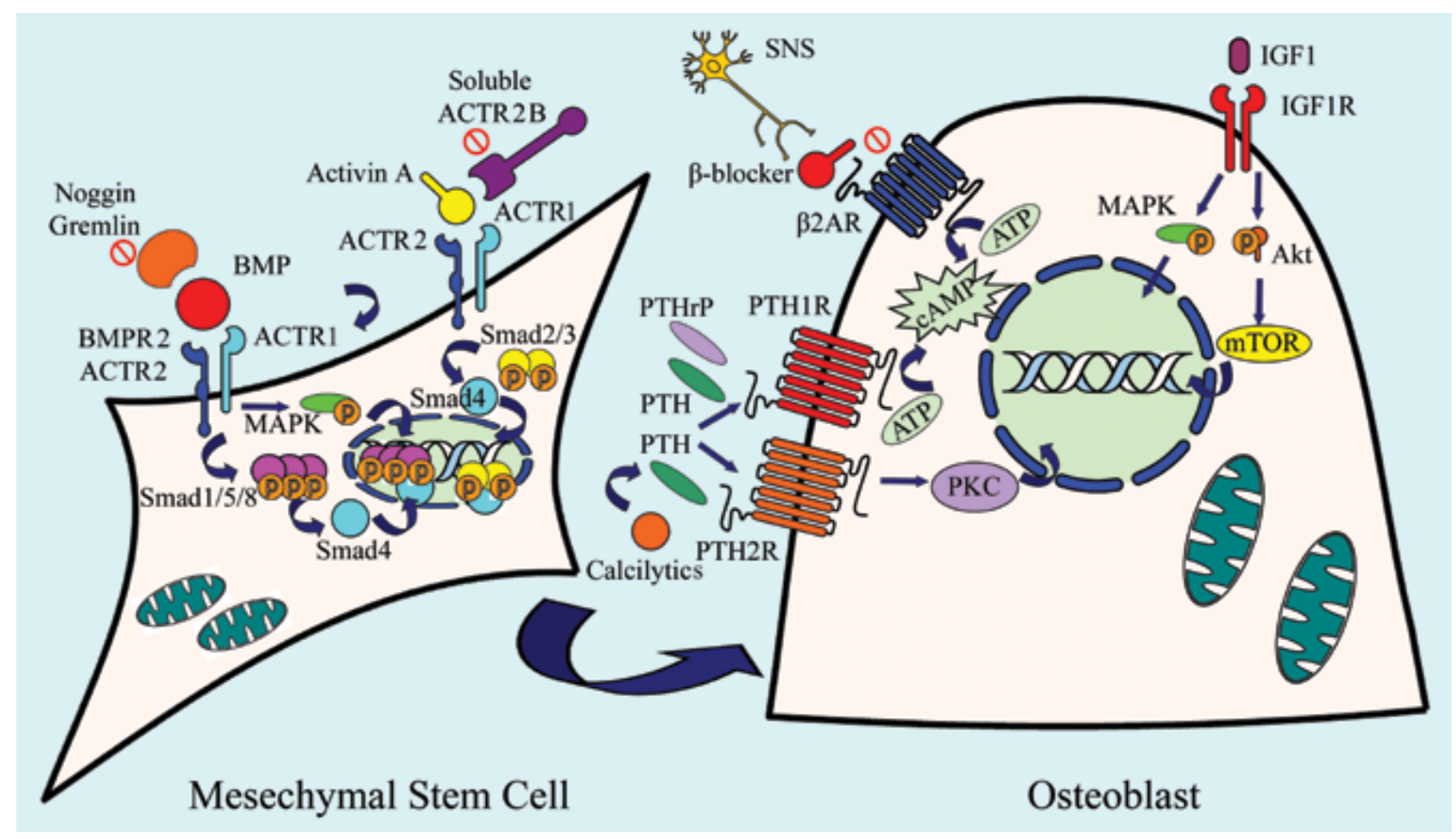

Figure 2. Molecular targets of the current and experimental bone anabolic therapies in the osteoblast and/or its progenitor cell. ACT: activin-type; ATP: adenosine triphosphate; $\beta 2 \mathrm{AR}$ : b2-andrenergic receptor; BMP: bone morphogenic protein; cAMP: cyclic adenosine monophosphate; IGF1: insulin-like growth factor 1; mTOR: mammalian targer of rapamycin; MAPK: mitogen-activated protein kinase; R: receptor; PKC: protein kinase C; PTH: parathyroid hormone; PTHrP: PTH-related peptide; SNS: sympathetic nervous system. 


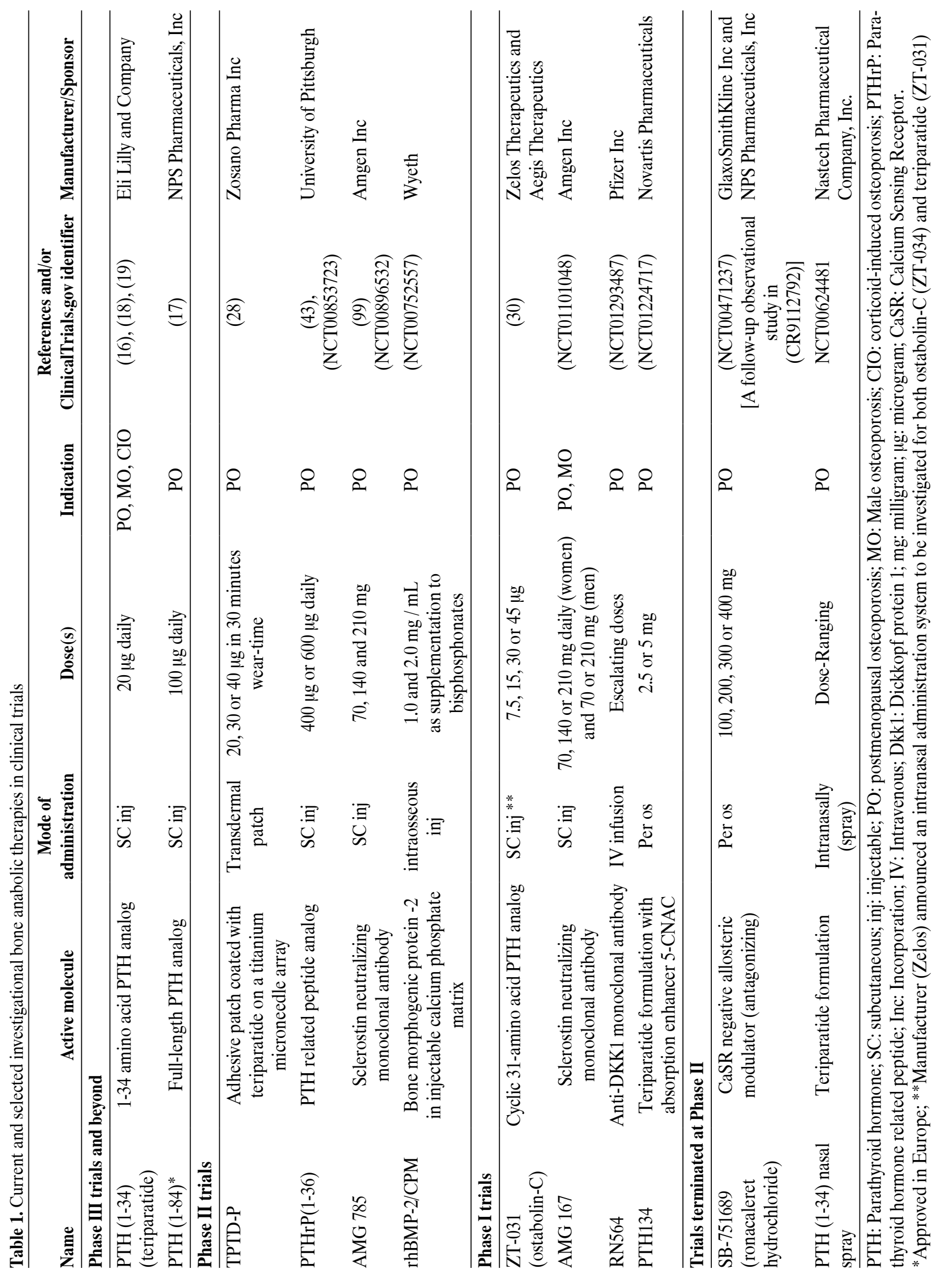




\section{Conflict of interest: The authors declare no conflict of interest.}

\section{Grants or fellowship supports: None.}

\section{REFERENCES}

1. Manolagas SC, Parfitt AM, 2010 What old means to bone. Trends Endocrinol Metab 21: 369-374.

2. Manolagas SC, 2010 From estrogen-centric to aging and oxidative stress: a revised perspective of the pathogenesis of osteoporosis. Endocr Rev 31: 266-300.

3. Lyritis GP, Georgoulas T, Zafeiris CP, 2010 Bone anabolic versus bone anticatabolic treatment of postmenopausal osteoporosis. Ann N Y Acad Sci 1205: 277-283.

4. Trivedi R, Goswami R, Chattopadhyay N, 2010 Investigational anabolic therapies for osteoporosis. Expert Opin Investig Drugs 19: 995-1005.

5. Borggrefe J, Graeff C, Nickelsen TN, Marin F, Gluer CC, 2010 Quantitative computed tomographic assessment of the effects of 24 months of teriparatide treatment on $3 \mathrm{D}$ femoral neck bone distribution, geometry, and bone strength: results from the EUROFORS study. J Bone Miner Res 25: 472-481.

6. Hodsman AB, Bauer DC, Dempster DW, et al, 2005 Parathyroid hormone and teriparatide for the treatment of osteoporosis: a review of the evidence and suggested guidelines for its use. Endocr Rev 26: 688-703.

7. Jilka RL, 2007 Molecular and cellular mechanisms of the anabolic effect of intermittent PTH. Bone 40: 1434-1446.

8. Corrado A, Neve A, Maruotti N, Gaudio A, Marucci A, Cantatore FP, 2011 Dose-dependent metabolic effect of zoledronate on primary human osteoblastic cell cultures. Clin Exp Rheumatol 28: 873-879.

9. Koch FP, Merkel C, Al-Nawas B, et al, 2010 Zoledronate, ibandronate and clodronate enhance osteoblast differentiation in a dose dependent manner - A quantitative in vitro gene expression analysis of Dlx5, Runx2, OCN, MSX1 and MSX2. J Craniomaxillofac Surg Epub ahead of print: PMID: 21030265.

10. Allen MR, Follet H, Khurana M, Sato M, Burr DB, 2006 Antiremodeling agents influence osteoblast activity differently in modeling and remodeling sites of canine rib. Calcif Tissue Int 79: 255-261.

11. Ma YL, Zeng QQ, Porras LL, et al, 2011 Teriparatide [rhPTH (1-34)], But Not Strontium Ranelate, Demonstrated Bone Anabolic Efficacy in Mature, Osteopenic, Ovariectomized Rats. Endocrinology 152: 1767-1778.

12. Jilka RL, Weinstein RS, Bellido T, Roberson P, Parfitt AM, Manolagas SC, 1999 Increased bone formation by prevention of osteoblast apoptosis with parathyroid hormone. J Clin Invest 104: 439-446.

13. Keller H, Kneissel M, 2005 SOST is a target gene for PTH in bone. Bone 37: 148-158.

14. Canalis E, 2010 Update in new anabolic therapies for osteoporosis. J Clin Endocrinol Metab 95: 1496-1504.

15. Martin TJ, Sims NA, Ng KW, 2008 Regulatory pathways revealing new approaches to the development of anabolic drugs for osteoporosis. Osteoporos Int 19: 1125-1138.

16. Trivedi R, Mithal A, Chattopadhyay N, 2010 Anabolics in osteoporosis: the emerging therapeutic tool. Curr Mol Med 10: 14-28.

17. Neer RM, Arnaud CD, Zanchetta JR, et al, 2001 Effect of parathyroid hormone (1-34) on fractures and bone mineral density in postmenopausal women with osteoporosis. N Engl J Med 344: 1434-1441.

18. Greenspan SL, Bone HG, Ettinger MP, et al, 2007 Effect of recombinant human parathyroid hormone (1-84) on vertebral fracture and bone mineral density in postmenopausal women with osteoporosis: a randomized trial. Ann Intern Med 146: 326-339.

19. Orwoll ES, Scheele WH, Paul S, et al, 2003 The effect of teriparatide [human parathyroid hormone (1-34)] therapy on bone density in men with osteoporosis. J Bone Miner Res 18: 9-17.

20. Saag KG, Zanchetta JR, Devogelaer JP, et al, 2009 Effects of teriparatide versus alendronate for treating glucocorticoid-induced osteoporosis: thirty-six-month results of a randomized, double-blind, controlled trial. Arthritis Rheum 60: 3346-3355.

21. Vahle JL, Sato M, Long GG, et al, 2002 Skeletal changes in rats given daily subcutaneous injections of recombinant human parathyroid hormone (1-34) for 2 years and relevance to human safety. Toxicol Pathol 30: 312-321.

22. Jolette J, Wilker CE, Smith SY, et al, 2006 Defining a noncarcinogenic dose of recombinant human parathyroid hormone 1-84 in a 2-year study in Fischer 344 rats. Toxicol Pathol 34: 929-940.

23. Obermayer-Pietsch BM, Marin F, McCloskey EV, et al, 2008 Effects of two years of daily teriparatide treatment on BMD in postmenopausal women with severe osteoporosis with and without prior antiresorptive treatment. J Bone Miner Res 23: 1591-1600.

24. Zanchetta JR, Bogado CE, Cisari C, et al, 2010 Treatment of postmenopausal women with osteoporosis with PTH(1-84) for 36 months: treatment extension study. Curr Med Res Opin 26: 2627-2633.

25. Hodsman AB, Hanley DA, Ettinger MP, et al, 2003 Efficacy and safety of human parathyroid hormone-(1-84) in increasing bone mineral density in postmenopausal osteoporosis. J Clin Endocrinol Metab 88: 5212-5220.

26. Gallacher SJ, Dixon T, 2010 Impact of treatments for postmenopausal osteoporosis (bisphosphonates, parathyroid hormone, strontium ranelate, and denosumab) on bone quality: a systematic review. Calcif Tissue Int 87: 469-484.

27. Foster SA, Foley KA, Meadows ES, et al, 2011 Adherence and persistence with teriparatide among patients with commercial, Medicare, and Medicaid insurance. Osteoporos Int 22: 551-557. 
28. Bauer DC, 2011 Discontinuation of odanacatib and other osteoporosis treatments: here today and gone tomorrow? J Bone Miner Res 26: 239-241.

29. Lane NE, Silverman SL, 2010 Anabolic therapies. Curr Osteoporos Rep 8: 23-27.

30. Cosman F, Lane NE, Bolognese MA, et al, 2010 Effect of transdermal teriparatide administration on bone mineral density in postmenopausal women. J Clin Endocrinol Metab 95: 151-158.

31. Matsumoto T, Shiraki M, Hagino H, Iinuma H, Nakamura T, 2006 Daily nasal spray of hPTH(1-34) for 3 months increases bone mass in osteoporotic subjects: a pilot study. Osteoporos Int 17: 1532-1538.

32. Nemeth EF, 2008 ZT-031, a cyclized analog of parathyroid hormone(1-31) for the potential treatment of osteoporosis. IDrugs 11: 827-840.

33. Strewler GJ, 2000 The physiology of parathyroid hormone-related protein. N Engl J Med 342: 177-185.

34. Makras P, Papapoulos SE, 2009 Medical treatment of hypercalcaemia. Hormones (Athens) 8: 83-95.

35. Datta NS, Abou-Samra AB, 2009 PTH and PTHrP signaling in osteoblasts. Cell Signal 21: 1245-1254.

36. Karaplis AC, Luz A, Glowacki J, et al, 1994 Lethal skeletal dysplasia from targeted disruption of the parathyroid hormone-related peptide gene. Genes Dev 8: 277-289.

37. Amizuka N, Karaplis AC, Henderson JE, et al, 1996 Haploinsufficiency of parathyroid hormone-related peptide (PTHrP) results in abnormal postnatal bone development. Dev Biol 175: 166-176.

38. Miao D, He B, Jiang Y, et al, 2005 Osteoblast-derived $\mathrm{PTHrP}$ is a potent endogenous bone anabolic agent that modifies the therapeutic efficacy of administered PTH 1-34. J Clin Invest 115: 2402-2411.

39. Kartsogiannis V, Moseley J, McKelvie B, et al, 1997 Temporal expression of PTHrP during endochondral bone formation in mouse and intramembranous bone formation in an in vivo rabbit model. Bone 21: 385-392.

40. Stewart AF, Mangin M, Wu T, et al, 1988 Synthetic human parathyroid hormone-like protein stimulates bone resorption and causes hypercalcemia in rats. $\mathrm{J}$ Clin Invest 81: 596-600.

41. Henry JG, Mitnick M, Dann PR, Stewart AF, 1997 Parathyroid hormone-related protein-(1-36) is biologically active when administered subcutaneously to humans. J Clin Endocrinol Metab 82: 900-906.

42. Plotkin H, Gundberg C, Mitnick M, Stewart AF, 1998 Dissociation of bone formation from resorption during 2-week treatment with human parathyroid hormonerelated peptide-(1-36) in humans: potential as an anabolic therapy for osteoporosis. J Clin Endocrinol Metab 83: 2786-2791.

43. Horwitz MJ, Tedesco MB, Gundberg C, Garcia-Ocana A, Stewart AF, 2003 Short-term, high-dose parathyroid hormone-related protein as a skeletal anabolic agent for the treatment of postmenopausal osteoporosis. J Clin
Endocrinol Metab 88: 569-575.

44. Horwitz MJ, Tedesco MB, Sereika SM, et al, 2006 Safety and tolerability of subcutaneous PTHrP(1-36) in healthy human volunteers: a dose escalation study. Osteoporos Int 17: 225-230.

45. Horwitz MJ, Tedesco MB, Garcia-Ocana A, et al, 2010 Parathyroid hormone-related protein for the treatment of postmenopausal osteoporosis: defining the maximal tolerable dose. J Clin Endocrinol Metab 95: 1279-1287.

46. Brown EM, 2000 Calcium receptor and regulation of parathyroid hormone secretion. Rev Endocr Metab Disord 1: 307-315.

47. Steddon SJ, Cunningham J, 2005 Calcimimetics and calcilytics--fooling the calcium receptor. Lancet 365 : 2237-2239.

48. Petrel C, Kessler A, Dauban P, Dodd RH, Rognan D, Ruat M, 2004 Positive and negative allosteric modulators of the $\mathrm{Ca} 2+$-sensing receptor interact within overlapping but not identical binding sites in the transmembrane domain. J Biol Chem 279: 18990-18997.

49. Gowen M, Stroup GB, Dodds RA, et al, 2000 Antagonizing the parathyroid calcium receptor stimulates parathyroid hormone secretion and bone formation in osteopenic rats. J Clin Invest 105: 1595-1604.

50. Saidak Z, Brazier M, Kamel S, Mentaverri R, 2009 Agonists and allosteric modulators of the calciumsensing receptor and their therapeutic applications. Mol Pharmacol 76: 1131-1144.

51. Chang W, Tu C, Cheng Z, et al, 2007 Complex formation with the Type $\mathrm{B}$ gamma-aminobutyric acid receptor affects the expression and signal transduction of the extracellular calcium-sensing receptor. Studies with HEK-293 cells and neurons. J Biol Chem 282: 2503025040.

52. Kumar S, Matheny CJ, Hoffman SJ, et al, 2010 An orally active calcium-sensing receptor antagonist that transiently increases plasma concentrations of PTH and stimulates bone formation. Bone 46: 534-542.

53. Fitzpatrick LA, Dabrowski CE, Cicconetti G, et al, 2011 The Effects of Ronacaleret, a Calcium-Sensing Receptor Antagonist, on Bone Mineral Density and Biochemical Markers of Bone Turnover in Postmenopausal Women with Low Bone Mineral Density. J Clin Endocrinol Metab Epub ahead of print: PMID: 21593114.

54. Balan G, Bauman J, Bhattacharya S, et al, 2009 The discovery of novel calcium sensing receptor negative allosteric modulators. Bioorg Med Chem Lett 19: 33283332.

55. Yoshida M, Mori A, Kotani E, et al, 2011 Discovery of Novel and Potent Orally Active Calcium-Sensing Receptor Antagonists that Stimulate Pulselike Parathyroid Hormone Secretion: Synthesis and Structure-Activity Relationships of Tetrahydropyrazolopyrimidine Derivatives. J Med Chem 54: 1430-1440.

56. Widler L, Altmann E, Beerli R, et al, 2010 1-Alkyl-4phenyl-6-alkoxy-1H-quinazolin-2-ones: a novel series 
of potent calcium-sensing receptor antagonists. J Med Chem 53: 2250-2263.

57. Marie PJ, 2010 The calcium-sensing receptor in bone cells: a potential therapeutic target in osteoporosis. Bone 46: 571-576.

58. Sun J, Murphy E, 2010 Calcium-sensing receptor: a sensor and mediator of ischemic preconditioning in the heart. Am J Physiol Heart Circ Physiol 299: H1309H1317.

59. Hurtel-Lemaire AS, Mentaverri R, Caudrillier A, et al, 2009 The calcium-sensing receptor is involved in strontium ranelate-induced osteoclast apoptosis. New insights into the associated signaling pathways. J Biol Chem 284: 575-584.

60. Ma Y, Nyman JS, Tao H, Moss HH, Yang X, Elefteriou F, 2011 \{beta\}2-Adrenergic Receptor Signaling in Osteoblasts Contributes to the Catabolic Effect of Glucocorticoids on Bone. Endocrinology 152: 1412-1422.

61. Elefteriou F, Ahn JD, Takeda S, et al, 2005 Leptin regulation of bone resorption by the sympathetic nervous system and CART. Nature 434: 514-520.

62. Takeda S, Elefteriou F, Levasseur R, et al, 2002 Leptin regulates bone formation via the sympathetic nervous system. Cell 111: 305-317.

63. Graham S, Hammond-Jones D, Gamie Z, Polyzois I, Tsiridis E, 2008 The effect of beta-blockers on bone metabolism as potential drugs under investigation for osteoporosis and fracture healing. Expert Opin Investig Drugs 17: 1281-1299.

64. Kondo H, Togari A, Continuous treatment with a lowdose beta-agonist reduces bone mass by increasing bone resorption without suppressing bone formation. Calcif Tissue Int 88: 23-32.

65. Bonnet N, Benhamou CL, Malaval L, et al, 2008 Low dose beta-blocker prevents ovariectomy-induced bone loss in rats without affecting heart functions. J Cell Physiol 217: 819-827.

66. Schlienger RG, Kraenzlin ME, Jick SS, Meier CR, 2004 Use of beta-blockers and risk of fractures. JAMA 292: 1326-1332.

67. de Vries F, Souverein PC, Cooper C, Leufkens HG, van Staa TP, 2007 Use of beta-blockers and the risk of hip/femur fracture in the United Kingdom and The Netherlands. Calcif Tissue Int 80: 69-75.

68. de Vries F, Pouwels S, Bracke M, et al, 2007 Use of beta-2 agonists and risk of hip/femur fracture: a populationbased case-control study. Pharmacoepidemiol Drug Saf 16: 612-619.

69. Wiens M, Etminan M, Gill SS, Takkouche B, 2006 Effects of antihypertensive drug treatments on fracture outcomes: a meta-analysis of observational studies. J Intern Med 260: 350-362.

70. Bonnet N, Gadois C, McCloskey E, et al, 2007 Protective effect of beta blockers in postmenopausal women: influence on fractures, bone density, micro and macroarchitecture. Bone 40: 1209-1216.
71. Meisinger C, Heier M, Lang O, Doring A, 2007 Betablocker use and risk of fractures in men and women from the general population: the MONICA/KORA Augsburg cohort study. Osteoporos Int 18: 1189-1195.

72. Yang S, Nguyen ND, Center JR, Eisman JA, Nguyen TV, 2011 Association between beta-blocker use and fracture risk: The Dubbo Osteoporosis Epidemiology Study. Bone 48: 451-455.

73. Schmitt CP, Obry J, Feneberg R, et al, 2003 Beta1adrenergic blockade augments pulsatile PTH secretion in humans. J Am Soc Nephrol 14: 3245-3250.

74. Clevers H, $2006 \mathrm{Wnt} /$ beta-catenin signaling in development and disease. Cell 127: 469-480.

75. Semenov MV, Habas R, Macdonald BT, He X, 2007 SnapShot: Noncanonical Wnt Signaling Pathways. Cell 131: 1378.

76. Almeida M, Han L, Bellido T, Manolagas SC, Kousteni S, $2005 \mathrm{Wnt}$ proteins prevent apoptosis of both uncommitted osteoblast progenitors and differentiated osteoblasts by beta-catenin-dependent and -independent signaling cascades involving Src/ERK and phosphatidylinositol 3-kinase/AKT. J Biol Chem 280: 41342-41351.

77. Yavropoulou MP, Yovos JG, 2007 The role of the Wnt signaling pathway in osteoblast commitment and differentiation. Hormones (Athens) 6: 279-294.

78. Milat F, Ng KW, 2009 Is Wnt signalling the final common pathway leading to bone formation? Mol Cell Endocrinol 310: 52-62.

79. Aberle H, Bauer A, Stappert J, Kispert A, Kemler R, 1997 beta-catenin is a target for the ubiquitin-proteasome pathway. EMBO J 16: 3797-3804.

80. Mao J, Wang J, Liu B, et al, 2001 Low-density lipoprotein receptor-related protein-5 binds to Axin and regulates the canonical Wnt signaling pathway. Mol Cell 7: 801-809.

81. He X, Saint-Jeannet JP, Wang Y, Nathans J, Dawid I, Varmus H, 1997 A member of the Frizzled protein family mediating axis induction by Wnt-5A. Science 275: 1652-1654.

82. Kawano Y, Kypta R, 2003 Secreted antagonists of the Wnt signalling pathway. J Cell Sci 116: 2627-2634.

83. Topol L, Jiang X, Choi H, Garrett-Beal L, Carolan PJ, Yang Y, 2003 Wnt-5a inhibits the canonical Wnt pathway by promoting GSK-3-independent beta-catenin degradation. J Cell Biol 162: 899-908.

84. Bodine PV, Zhao W, Kharode YP, et al, 2004 The Wnt antagonist secreted frizzled-related protein-1 is a negative regulator of trabecular bone formation in adult mice. Mol Endocrinol 18: 1222-1237.

85. Semenov MV, Tamai K, Brott BK, Kuhl M, Sokol S, He X, 2001 Head inducer Dickkopf-1 is a ligand for Wnt coreceptor LRP6. Curr Biol 11: 951-961.

86. Mao B, Wu W, Davidson G, et al, 2002 Kremen proteins are Dickkopf receptors that regulate $\mathrm{Wnt} /$ beta-catenin signalling. Nature 417: 664-667.

87. Semenov M, Tamai K, He X, 2005 SOST is a ligand 
for LRP5/LRP6 and a Wnt signaling inhibitor. J Biol Chem 280: 26770-26775.

88. Gong Y, Slee RB, Fukai N, et al, 2001 LDL receptorrelated protein 5 (LRP5) affects bone accrual and eye development. Cell 107: 513-523.

89. Streeten EA, McBride D, Puffenberger E, et al, 2008 Osteoporosis-pseudoglioma syndrome: description of 9 new cases and beneficial response to bisphosphonates. Bone 43: 584-590.

90. Little RD, Carulli JP, Del Mastro RG, et al, 2002 A mutation in the LDL receptor-related protein 5 gene results in the autosomal dominant high-bone-mass trait. Am J Hum Genet 70: 11-19.

91. Boyden LM, Mao J, Belsky J, et al, 2002 High bone density due to a mutation in LDL-receptor-related protein 5. N Engl J Med 346: 1513-1521.

92. Van Wesenbeeck L, Cleiren E, Gram J, et al, 2003 Six novel missense mutations in the LDL receptor-related protein 5 (LRP5) gene in different conditions with an increased bone density. Am J Hum Genet 72: 763-771.

93. Mani A, Radhakrishnan J, Wang H, et al, 2007 LRP6 mutation in a family with early coronary disease and metabolic risk factors. Science 315: 1278-1282.

94. Balemans W, Ebeling M, Patel N, et al, 2001 Increased bone density in sclerosteosis is due to the deficiency of a novel secreted protein (SOST). Hum Mol Genet 10: 537-543.

95. Brunkow ME, Gardner JC, Van Ness J, et al, 2001 Bone dysplasia sclerosteosis results from loss of the SOST gene product, a novel cystine knot-containing protein. Am J Hum Genet 68: 577-589.

96. Loots GG, Kneissel M, Keller H, et al, 2005 Genomic deletion of a long-range bone enhancer misregulates sclerostin in Van Buchem disease. Genome Res 15: 928-935.

97. Moester MJ, Papapoulos SE, Lowik CW, van Bezooijen RL, 2010 Sclerostin: current knowledge and future perspectives. Calcif Tissue Int 87: 99-107.

98. Li X, Ominsky MS, Warmington KS, et al, 2009 Sclerostin antibody treatment increases bone formation, bone mass, and bone strength in a rat model of postmenopausal osteoporosis. J Bone Miner Res 24: 578-588.

99. Li X, Warmington KS, Niu QT, et al, 2010 Inhibition of sclerostin by monoclonal antibody increases bone formation, bone mass, and bone strength in aged male rats. J Bone Miner Res 25: 2371-2380.

100. Ominsky MS, Vlasseros F, Jolette J, et al, Two doses of sclerostin antibody in cynomolgus monkeys increases bone formation, bone mineral density, and bone strength. J Bone Miner Res 25: 948-959.

101. Padhi D, Jang G, Stouch B, Fang L, Posvar E, 2011 Single-dose, placebo-controlled, randomized study of AMG 785, a sclerostin monoclonal antibody. J Bone Miner Res 26: 19-26.

102. Lewiecki EM, 2011 Sclerostin monoclonal antibody therapy with AMG 785: a potential treatment for osteoporosis. Expert Opin Biol Ther 11: 117-127.

103. Agholme F, Li X, Isaksson H, Ke HZ, Aspenberg P, 2010 Sclerostin antibody treatment enhances metaphyseal bone healing in rats. J Bone Miner Res 25: 2412-2418.

104. Yaccoby S, Ling W, Zhan F, Walker R, Barlogie B, Shaughnessy JD, Jr., 2007 Antibody-based inhibition of DKK1 suppresses tumor-induced bone resorption and multiple myeloma growth in vivo. Blood 109: 2106-2111.

105. Betts AM, Clark TH, Yang J, et al, 2010 The application of target information and preclinical pharmacokinetic/ pharmacodynamic modeling in predicting clinical doses of a Dickkopf-1 antibody for osteoporosis. J Pharmacol Exp Ther 333: 2-13.

106. Clement-Lacroix P, Ai M, Morvan F, et al, 2005 Lrp5independent activation of Wnt signaling by lithium chloride increases bone formation and bone mass in mice. Proc Natl Acad Sci U S A 102: 17406-17411.

107. Kulkarni NH, Onyia JE, Zeng Q, et al, 2006 Orally bioavailable GSK-3alpha/beta dual inhibitor increases markers of cellular differentiation in vitro and bone mass in vivo. J Bone Miner Res 21: 910-920.

108. Bodine PV, Stauffer B, Ponce-de-Leon H, et al, 2009 A small molecule inhibitor of the Wnt antagonist secreted frizzled-related protein-1 stimulates bone formation. Bone 44: 1063-1068.

109. Bliziotes M, 2011 Update in serotonin and bone. J Clin Endocrinol Metab 95: 4124-4132.

110. Yadav VK, Ducy P, 2010 Lrp5 and bone formation: A serotonin-dependent pathway. Ann N Y Acad Sci 1192: 103-109.

111. Karsenty G, Yadav VK, 2011 Regulation of bone mass by serotonin: molecular biology and therapeutic implications. Annu Rev Med 62: 323-331.

112. Yadav VK, Oury F, Suda N, et al, 2009 A serotonindependent mechanism explains the leptin regulation of bone mass, appetite, and energy expenditure. Cell 138: 976-989.

113. Cui Y, Niziolek PJ, Macdonald BT, et al, 2011 Lrp5 functions in bone to regulate bone mass. Nat Med 17: 684-691.

114. Yadav VK, Ryu JH, Suda N, et al, 2008 Lrp5 controls bone formation by inhibiting serotonin synthesis in the duodenum. Cell 135: 825-837.

115. Yadav VK, Balaji S, Suresh PS, et al, 2010 Pharmacological inhibition of gut-derived serotonin synthesis is a potential bone anabolic treatment for osteoporosis. Nat Med 16: 308-312.

116. Warden SJ, Robling AG, Sanders MS, Bliziotes MM, Turner CH, 2005 Inhibition of the serotonin (5-hydroxytryptamine) transporter reduces bone accrual during growth. Endocrinology 146: 685-693.

117. Westbroek I, Waarsing JH, van Leeuwen JP, et al, 2007 Long-term fluoxetine administration does not result 
in major changes in bone architecture and strength in growing rats. J Cell Biochem 101: 360-368.

118. Kinjo M, Setoguchi S, Schneeweiss S, Solomon DH, 2005 Bone mineral density in subjects using central nervous system-active medications. Am J Med 118: 1414.

119. Spangler L, Scholes D, Brunner RL, et al, 2008 Depressive symptoms, bone loss, and fractures in postmenopausal women. J Gen Intern Med 23: 567-574.

120. Richards JB, Papaioannou A, Adachi JD, et al, 2007 Effect of selective serotonin reuptake inhibitors on the risk of fracture. Arch Intern Med 167: 188-194.

121. Haney EM, Chan BK, Diem SJ, et al, 2007 Association of low bone mineral density with selective serotonin reuptake inhibitor use by older men. Arch Intern Med 167: 1246-1251.

122. Diem SJ, Blackwell TL, Stone KL, et al, 2007 Use of antidepressants and rates of hip bone loss in older women: the study of osteoporotic fractures. Arch Intern Med 167: 1240-1245.

123. Vestergaard P, 2009 Fracture risks of antidepressants. Expert Rev Neurother 9: 137-141.

124. Bolton JM, Metge C, Lix L, Prior H, Sareen J, Leslie WD, 2008 Fracture risk from psychotropic medications: a population-based analysis. J Clin Psychopharmacol 28: 384-391.

125. Lewis CE, Ewing SK, Taylor BC, et al, 2007 Predictors of non-spine fracture in elderly men: the MrOS study. J Bone Miner Res 22: 211-219.

126. Ziere G, Dieleman JP, van der Cammen TJ, Hofman A, Pols HA, Stricker BH, 2008 Selective serotonin reuptake inhibiting antidepressants are associated with an increased risk of nonvertebral fractures. J Clin Psychopharmacol 28: 411-417.

127. Hubbard R, Farrington P, Smith C, Smeeth L, Tattersfield A, 2003 Exposure to tricyclic and selective serotonin reuptake inhibitor antidepressants and the risk of hip fracture. Am J Epidemiol 158: 77-84.

128. Verdel BM, Souverein PC, Egberts TC, van Staa TP, Leufkens HG, de Vries F, Use of antidepressant drugs and risk of osteoporotic and non-osteoporotic fractures. Bone 47: 604-609.

129. Modder UI, Achenbach SJ, Amin S, Riggs BL, Melton LJ, 3rd, Khosla S, 2010 Relation of serum serotonin levels to bone density and structural parameters in women. J Bone Miner Res 25: 415-422.

130. Bilezikjian LM, Blount AL, Donaldson CJ, Vale WW, 2006 Pituitary actions of ligands of the TGF-beta family: activins and inhibins. Reproduction 132: 207-215.

131. Zaidi M, Blair HC, Iqbal J, et al, 2009 New insights: elevated follicle-stimulating hormone and bone loss during the menopausal transition. Curr Rheumatol Rep 11: 191-195.

132. Reame NE, Lukacs JL, Olton P, Ansbacher R, Padmanabhan V, 2007 Differential effects of aging on activin $\mathrm{A}$ and its binding protein, follistatin, across the menopause transition. Fertil Steril 88: 1003-1005.

133. Eijken M, Swagemakers S, Koedam M, et al, 2007 The activin A-follistatin system: potent regulator of human extracellular matrix mineralization. FASEB J 21: 2949-2960.

134. Oue Y, Kanatani H, Kiyoki M, Eto Y, Ogata E, Matsumoto T, 1994 Effect of local injection of activin A on bone formation in newborn rats. Bone 15: 361-366.

135. Hashimoto M, Shoda A, Inoue S, et al, 1992 Functional regulation of osteoblastic cells by the interaction of activin-A with follistatin. J Biol Chem 267: 4999-5004.

136. Ikenoue T, Jingushi S, Urabe K, Okazaki K, Iwamoto Y, 1999 Inhibitory effects of activin-A on osteoblast differentiation during cultures of fetal rat calvarial cells. J Cell Biochem 75: 206-214.

137. Vale W, Wiater E, Gray P, Harrison C, Bilezikjian L, Choe S, 2004 Activins and inhibins and their signaling. Ann N Y Acad Sci 1038: 142-147.

138. Vallet S, Mukherjee S, Vaghela N, et al, 2010 Activin A promotes multiple myeloma-induced osteolysis and is a promising target for myeloma bone disease. Proc Natl Acad Sci U S A 107: 5124-5129.

139. Sun L, Peng Y, Sharrow AC, et al, 2006 FSH directly regulates bone mass. Cell 125: 247-260.

140. Prior JC, 2007 FSH and bone--important physiology or not? Trends Mol Med 13: 1-3.

141. Sakai R, Miwa K, Eto Y, 1999 Local administration of activin promotes fracture healing in the rat fibula fracture model. Bone 25: 191-196.

142. Pearsall RS, Canalis E, Cornwall-Brady M, et al, 2008 A soluble activin type IIA receptor induces bone formation and improves skeletal integrity. Proc Natl Acad Sci U S A 105: 7082-7087.

143. Koncarevic A, Cornwall-Brady M, Pullen A, et al, 2010 A soluble activin receptor type IIb prevents the effects of androgen deprivation on body composition and bone health. Endocrinology 151: 4289-4300.

144. Ogawa Y, Schmidt DK, Nathan RM, et al, 1992 Bovine bone activin enhances bone morphogenetic proteininduced ectopic bone formation. J Biol Chem 267: 14233-14237.

145. Gaddy-Kurten D, Coker JK, Abe E, Jilka RL, Manolagas SC, 2002 Inhibin suppresses and activin stimulates osteoblastogenesis and osteoclastogenesis in murine bone marrow cultures. Endocrinology 143: 74-83.

146. Fajardo RJ, Manoharan RK, Pearsall RS, et al, 2010 Treatment with a soluble receptor for activin improves bone mass and structure in the axial and appendicular skeleton of female cynomolgus macaques (Macaca fascicularis). Bone 46: 64-71.

147. Lotinun S, Pearsall RS, Davies MV, et al, 2010 A soluble activin receptor Type IIA fusion protein (ACE-011) increases bone mass via a dual anabolic-antiresorptive effect in Cynomolgus monkeys. Bone 46: 1082-1088.

148. Ruckle J, Jacobs M, Kramer W, et al, 2009 Single-dose, randomized, double-blind, placebo-controlled study of 
ACE-011 (ActRIIA-IgG1) in postmenopausal women. J Bone Miner Res 24: 744-752.

149. Canalis E, 2009 Growth factor control of bone mass. J Cell Biochem 108: 769-777.

150. Canalis E, Economides AN, Gazzerro E, 2003 Bone morphogenetic proteins, their antagonists, and the skeleton. Endocr Rev 24: 218-235.

151. Daluiski A, Engstrand T, Bahamonde ME, et al, 2001 Bone morphogenetic protein-3 is a negative regulator of bone density. Nat Genet 27: 84-88.

152. Payne C, King J, Hay D, 2011 The role of activin/nodal and Wnt signaling in endoderm formation. Vitam Horm 85: 207-216.

153. Kamiya N, Ye L, Kobayashi T, et al, 2008 BMP signaling negatively regulates bone mass through sclerostin by inhibiting the canonical Wnt pathway. Development 135: 3801-3811.

154. Axelrad TW, Einhorn TA, 2009 Bone morphogenetic proteins in orthopaedic surgery. Cytokine Growth Factor Rev 20: 481-488.

155. El-Amin SF, Hogan MV, Allen AA, Hinds J, Laurencin CT, 2010 The indications and use of bone morphogenetic proteins in foot, ankle, and tibia surgery. Foot Ankle Clin 15: 543-551.

156. Kanakaris NK, Petsatodis G, Tagil M, Giannoudis PV, 2009 Is there a role for bone morphogenetic proteins in osteoporotic fractures? Injury 40 Suppl 3: S21-S26.

157. Matsumoto A, Yamaji K, Kawanami M, Kato H, 2001 Effect of aging on bone formation induced by recombinant human bone morphogenetic protein- 2 combined with fibrous collagen membranes at subperiosteal sites. J Periodontal Res 36: 175-182.

158. Turgeman G, Zilberman Y, Zhou S, et al, 2002 Systemically administered rhBMP-2 promotes MSC activity and reverses bone and cartilage loss in osteopenic mice. J Cell Biochem 86: 461-474.

159. Simic P, Culej JB, Orlic I, et al, 2006 Systemically administered bone morphogenetic protein- 6 restores bone in aged ovariectomized rats by increasing bone formation and suppressing bone resorption. J Biol Chem 281: 25509-25521.

160. Phillips FM, Voronov LI, Gaitanis IN, Carandang G, Havey RM, Patwardhan AG, 2006 Biomechanics of posterior dynamic stabilizing device (DIAM) after facetectomy and discectomy. Spine J 6: 714-722.

161. Rose T, Peng H, Usas A, Josten C, Fu FH, Huard J, 2005 [Ex-vivo gene therapy with BMP-4 for critically sized defects and enhancement of fracture healing in an osteoporotic animal model]. Unfallchirurg 108: 25-34.

162. Tang DZ, Hou W, Zhou Q, et al, 2010 Osthole stimulates osteoblast differentiation and bone formation by activation of beta-catenin-BMP signaling. J Bone Miner Res 25: 1234-1245.

163. Lee SU, Park SJ, Kwak HB, Oh J, Min YK, Kim SH, 2008 Anabolic activity of ursolic acid in bone: Stimulat- ing osteoblast differentiation in vitro and inducing new bone formation in vivo. Pharmacol Res 58: 290-296.

164. Chang JK, Hsu YL, Teng IC, Kuo PL, 2006 Piceatannol stimulates osteoblast differentiation that may be mediated by increased bone morphogenetic protein-2 production. Eur J Pharmacol 551: 1-9.

165. Wu JB, Fong YC, Tsai HY, Chen YF, Tsuzuki M, Tang $\mathrm{CH}, 2008$ Naringin-induced bone morphogenetic protein-2 expression via PI3K, Akt, c-Fos/c-Jun and AP-1 pathway in osteoblasts. Eur J Pharmacol 588: 333-341.

166. Takayama K, Suzuki A, Manaka T, et al, 2009 RNA interference for noggin enhances the biological activity of bone morphogenetic proteins in vivo and in vitro. J Bone Miner Metab 27: 402-411.

167. Gazzerro E, Smerdel-Ramoya A, Zanotti S, et al, 2007 Conditional deletion of gremlin causes a transient increase in bone formation and bone mass. J Biol Chem 282: 31549-31557.

168. Garrison KR, Shemilt I, Donell S, et al, 2010 Bone morphogenetic protein (BMP) for fracture healing in adults. Cochrane Database Syst Rev: CD006950.

169. Bessa PC, Balmayor ER, Hartinger J, et al, 2010 Silk fibroin microparticles as carriers for delivery of human recombinant bone morphogenetic protein-2: in vitro and in vivo bioactivity. Tissue Eng Part C Methods 16: 937-945.

170. Ghiron LJ, Thompson JL, Holloway L, et al, 1995 Effects of recombinant insulin-like growth factor-I and growth hormone on bone turnover in elderly women. J Bone Miner Res 10: 1844-1852.

171. Rudman D, Feller AG, Nagraj HS, et al, 1990 Effects of human growth hormone in men over 60 years old. N Engl J Med 323: 1-6.

172. Canalis EM, Hintz RL, Dietrich JW, Maina DM, Raisz LG, 1977 Effect of somatomedin and growth hormone on bone collagen synthesis in vitro. Metabolism 26: 1079-1087.

173. Canalis E, 1980 Effect of insulinlike growth factor I on DNA and protein synthesis in cultured rat calvaria. J Clin Invest 66: 709-719.

174. Isgaard J, Nilsson A, Lindahl A, Jansson JO, Isaksson OG, 1986 Effects of local administration of GH and IGF-1 on longitudinal bone growth in rats. Am J Physiol 250: E367-E372.

175. Spencer EM, Liu CC, Si EC, Howard GA, 1991 In vivo actions of insulin-like growth factor-I (IGF-I) on bone formation and resorption in rats. Bone 12: 21-6.

176. Holmes SJ, Economou G, Whitehouse RW, Adams JE, Shalet SM, 1994 Reduced bone mineral density in patients with adult onset growth hormone deficiency. J Clin Endocrinol Metab 78: 669-674.

177. Johansson AG, Burman P, Westermark K, Ljunghall S, 1992 The bone mineral density in acquired growth hormone deficiency correlates with circulating levels of insulin-like growth factor I. J Intern Med 232: 447-452. 
178. Wuster C, Abs R, Bengtsson BA, et al, 2001 The influence of growth hormone deficiency, growth hormone replacement therapy, and other aspects of hypopituitarism on fracture rate and bone mineral density. J Bone Miner Res 16: 398-405.

179. Murray RD, Columb B, Adams JE, Shalet SM, 2004 Low bone mass is an infrequent feature of the adult growth hormone deficiency syndrome in middle-age adults and the elderly. J Clin Endocrinol Metab 89: 1124-1130.

180. Colao A, Di Somma C, Cuocolo A, et al, 2004 The severity of growth hormone deficiency correlates with the severity of cardiac impairment in 100 adult patients with hypopituitarism: an observational, case-control study. J Clin Endocrinol Metab 89: 5998-6004.

181. Langlois JA, Rosen CJ, Visser M, et al, 1998 Association between insulin-like growth factor I and bone mineral density in older women and men: the Framingham Heart Study. J Clin Endocrinol Metab 83: 4257-4262.

182. Bex M, Abs R, Maiter D, Beckers A, Lamberigts G, Bouillon R, 2002 The effects of growth hormone replacement therapy on bone metabolism in adult-onset growth hormone deficiency: a 2-year open randomized controlled multicenter trial. J Bone Miner Res 17: 1081-1094.

183. Cuneo RC, Judd S, Wallace JD, et al, 1998 The Australian Multicenter Trial of Growth Hormone (GH) Treatment in GH-Deficient Adults. J Clin Endocrinol Metab 83: 107-116.

184. Hoffman AR, Kuntze JE, Baptista J, et al, 2004 Growth hormone $(\mathrm{GH})$ replacement therapy in adult-onset GH deficiency: effects on body composition in men and women in a double-blind, randomized, placebocontrolled trial. J Clin Endocrinol Metab 89: 2048-2056.

185. Baum HB, Biller BM, Finkelstein JS, et al, 1996
Effects of physiologic growth hormone therapy on bone density and body composition in patients with adult-onset growth hormone deficiency. A randomized, placebo-controlled trial. Ann Intern Med 125: 883-890.

186. Snyder PJ, Biller BM, Zagar A, et al, 2007 Effect of growth hormone replacement on BMD in adult-onset growth hormone deficiency. J Bone Miner Res 22: 762-770.

187. Holloway L, Butterfield G, Hintz RL, Gesundheit N, Marcus R, 1994 Effects of recombinant human growth hormone on metabolic indices, body composition, and bone turnover in healthy elderly women. J Clin Endocrinol Metab 79: 470-479.

188. Holloway L, Kohlmeier L, Kent K, Marcus R, 1997 Skeletal effects of cyclic recombinant human growth hormone and salmon calcitonin in osteopenic postmenopausal women. J Clin Endocrinol Metab 82: 1111-1117.

189. Aloia JF, Zanzi I, Ellis K, et al, 1976 Effects of growth hormone in osteoporosis. J Clin Endocrinol Metab 43: 992-999.

190. Kruse HP, Kuhlencordt F, 1975 On an attempt to treat primary and secondary osteoporosis with human growth hormone. Horm Metab Res 7: 488-491.

191. Aloia JF, Vaswani A, Kapoor A, Yeh JK, Cohn SH, 1985 Treatment of osteoporosis with calcitonin, with and without growth hormone. Metabolism 34: 124-129.

192. Friedlander AL, Butterfield GE, Moynihan S, et al, 2001 One year of insulin-like growth factor I treatment does not affect bone density, body composition, or psychological measures in postmenopausal women. J Clin Endocrinol Metab 86: 1496-1503.

193. Canalis E, Giustina A, Bilezikian JP, 2007 Mechanisms of anabolic therapies for osteoporosis. N Engl J Med 357: 905-916. 